\title{
JUAN BAUTISTA VIRIO (1753-1837): EXPERIENCIA EUROPEA Y REFORMISMO ECONOMICO EN LA ESPAÑA ILUSTRADA
}

\author{
Jesús PRADELLS NADAL \\ Universidad de Alicante
}

\section{JUAN BAUTISTA VIRIO}

Juan Bautista Virio es un personaje prácticamente desconocido para la historiografía. Las referencias bibliográficas sobre su persona son muy escasas. Godoy lo menciona en sus Memorias en un par de ocasiones como uno más de los cerebros que formaron su cohorte de especialistas en materias económicas y de fomento, pero ni Colmeiro ni Correa Calderón lo incluyeron en sus catálogos de escritores económicos, probablemente por su condición de extranjero, aunque toda su carrera la realizó al servicio de la monarquía española. Richard Herr tampoco reparó en su persona cuando dedicó unas páginas a la preocupación de los ministros del gabinete de Godoy por fomentar el conocimiento de los adelantos técnicos europeos. En esta misma línea, Fernando Díez se detuvo en hacer algunas consideraciones sobre su trayectoria personal con motivo de su participación en la fundación del Semanario de Agricultura y Artes. Por último, Pere Molas lo mencionaba al tratar de la Dirección de Fomento durante el breve espacio de tiempo que ésta estuvo bajo su dirección. Luego, el rastro de Virio se pierde, sin que se encuentren más alusiones a su posterior trayectoria que su inclusión en alguna de las listas de afrancesados ${ }^{1}$.

1 PRINCIPE DE LA PAZ: Memorias, 2 vois. Madrid 1965, I, pp. 196, n. 185, donde, al referirse a Melón, Portillo y Marcos como los encargados de la redacción de un nuevo plan de estudios universitarios, añade "y creo, también, Don Juan Bautista Virio". En I, pp. 227-228 lo incluye entre "...los españoles que en açuellos años se prestaron al impulso del gobierno y merecieron bien de la Patria, por su cooperación y sus esfuerzos, a multiplicar las luces y extenderlas". CORREA CALDERON, E.: Registro de arbitristas, economistas y reformadores... Madrid, 1982. COLMEIRO, M.: Biblioteca de los economistas..., Madrid, 1979 (5 ed.). HERR, R.: España y la revolucion del siglo XVIII, Madrid, 1971, pp. 323-324. DIEZ RODRIGUEZ, F.: Prensa Agraria en la España de la Ilustración. El Semanario de Agricultura y Artes dirigido a párrocos, (I797-1808), Madrid, 1980. MOLAS RIBALTA, P. : "De la Junta de Comercio al Ministerio de Fomento", en Actas del IV Symposium de Historia de la Administración. Madrid, 1983, pp. 529-556; especialmente pp. 536 y 538-543. MERCADER RIBA, J.: 'La diplomacia española de José Bonaparte", en Homenaje a Jaime Vicens-Vives, Barcelona 1967, II, pp. 409-425, especialmente pp. 418-419. 
Sin embargo, a pesar de no ser uno de los nombres más representativos, es una figura con caracteres extraordinarios entre los funcionarios proyectistas del último cuarto del siglo XVIII.

Pero, antes de pasar a referirnos a su labor, características generales de su pensamiento económico, y a su dimensión de proyectista en las postrimerías del siglo XVIII, no estará de más intentar una primera aproximación a su figura.

La biografía de Juan Bautista Virior o Virio, como se conocería su nombre españolizado, comenzó hacia 1753 en Pest, en los dominios patrimoniales de los Habsburgo. Por el momento, resulta prácticamente imposible hacer precisiones sobre su infancia y juventud, y por tanto acerca de la formación que recibió durante aquellos primeros años. Su origen social es bastante oscuro, pues, sólo en 1810 , manifestó ser descendiente de "una de las más nobles y antiguas familias de Lorena", venida a menos, como consecuencia de las guerras que asolaron la Europa del siglo XVII. Tampoco entre la documentación consultada aparecen, además de sus dos esposas, sino alusiones, igualmente tardías, a más familiares que a un hermano, dueño de un próspero establecimiento comercial en su ciudad natal, y a una hermana, por entonces viuda y cargada de hijos ${ }^{2}$.

A lo largo de su dilatada trayectoria vital estuvo, estrechamente condicionado por una naturaleza enfermiza, que se agravó con la aparición de una esquinencia, una angina de pecho en términos más actuales, y entre los mismos covachuelistas madrileños se consideró durante algún tiempo más que probable la asistencia a su sepelio, aunque no sólo erraron los pronósticos sino que, durante más de cuarenta años, sometido a climas cáusticos y azarosos viajes, consiguió Virio pasear sus malos humores físicos y anímico por media Europa.

Mayor huella que su precaria salud dejó en la Secretaría de Estado su carácter difícil y trato poco amable, sobre todo cuando se codeaba con personajes cuya categoría era inferior a la de Ministro plenipotenciario. Los testimonios que en este sentido hizo al propio Godoy su primera y santurrona esposa, Mariana Juana Costa, de la que se separaría tormentosamente en 1797 , los hubiésemos tomado con elemental prudencia, de no ser confirmados también por algunos indicios que aparecen en los oficios de régimen interno y, sobre todo, por las explícitas protestas de sus cualificados colegas y subordinados de la Dirección de Fomento ${ }^{3}$.

Virio no fue un economista teórico, como para su propia desgracia y la de su hacienda lo fue su contemporáneo Valentín de Foronda, sino, ante todo, un hombre dedicado a lo que él mismo denominaba en la terminología al uso "economía-política práctica". Su pensamiento no alcanza cotas de gran originalidad, pero, de hacernos eco de uno de los más reiterados lugares comunes, la ausencia de esta rara cualidad no es sorprendente entre los españoles del siglo XVIII. De hecho, sus planteamientos teóricos, los "sólidos principios de economía política", a que a menudo se refería él mismo, no difieren básicamente de los que caracterizaban a los más conspicuos ilustrados y protoliberales, que no llegaron a formular soluciones radicales de reforma. Una sabia política arancelaria, de carácter proteccionista; medidas desvinculadoras y

2 Expediente personal de Juan Bautista Virio. A.H.N. Estado, leg. 3.436 (2). Especialmente VirioCevallos, Viena, 8-10-1806.

3 Costa, María Juana-Príncipe de la Paz, Madrid, 22-11-1797. Bernabé Portillo-Juan Jose Piñuelas. Madrid, 8-1 1-1797. A.H.N. Estado, leg. 3.485. 
desamortizadoras en materia agraria, con un apoyo expreso del gobierno a la introducción de mejoras técnicas por parte de los "labradores y hacendados"; fomento de las manufacturas mediante la inversión racional de capitales; la importación de operarios cualificados; la mejor preparación de los gestores económinos y empresariales, que se debería complementar -de manera imprescindible-con una adecuada política mercantil; fomento de la "economía popular" y domiciliaria frente a los condicionantes negativos del caduco reglamentarismo de los gremios; desarrollo del sistema bancario conforme a las técnicas europeas; impulso de un amplio sistema de beneficencia formativa y educacional para acabar con el paro - "vagabundeo" -; creación de instituciones de enseñanza cualificada de agricultura, comercio y ciencias útiles, etc. Todo ello, amalgamado en un singular voluntarismo y gran confianza en los recursos del poder político para aumentar la riqueza de la nación.

En su obra destaca el elemento utilitarista, basado en el análisis comparativo de las medidas legislativas aplicadas por los diferentes Estados para el desarrollo de sus economías, de forma que se pudiera, no sólo aprender de la experiencia ajena, sino aplicar en España con conocimiento de causa aquellas que hubiesen demostrado una mayor eficacia. Excelente conocedor de la legislación económica británica, de Austria, de los Estados alemanes e incluso de Francia, Virio dedicó gran parte de su vida a la recopilación de obras, memorias, informes y toda clase de escritos sobre legislación y teoría económica de Europa, con los que redactaría decenas de informes destinados al Gobierno español.

De sus obras, tan sólo una, la Colección Alfabética de los Aranceles de la Gran Bretaña, fue publicada; otras dos, también de grueso calibre, permanecieron manuscritas: los Hechos de María Teresa de Austria y una Colección de los Aranceles de Austria.

De los cientos de informes que elaboró durante su larguísima carrera ninguno visitó las prensas, salvo unos artículos de carácter político aparecidos en el Diario de Madrid, pues no llegó a incluir ningún texto suyo en el Semanario de Agricultura y Artes, del que fue director durante un breve período.

En su mayor parte, los escritos de Virio fueron memorias sobre comercio y otros de tema económico más general, con un carácter eminentemente informativo y técnico sobre las providencias económicas inglesas, austriacas, alemanas y, en menor medida, francesas, destinados al uso interno de la Administración, y que elevó, con muy distinta fortuna, a los numerosos Secretarios de Estado que desfilaron por Palacio desde la caída de Floridablanca hasta mediada la década de 1830.

Muy diversa fortuna tuvo también personalmente en su vida. Aquejado por una pésima salud de hierro, casado con suerte desigual por dos veces, testigo directo de las contiendas napoleónicas, puesto que en Hamburgo vivió la invasión francesa y su conquista por las tropas rusas.

Las contradicciones laten también en su postura política. Gozó, con distinta intensidad, del favor de varios Embajadores, del omnipotente Floridablanca, del favorito Godoy y también de Cevallos. Menor predicamento tuvo con Saavedra y Urquijo. Afrancesado, y patriota constitucional en 1814, resultó represaliado en cada una de las restauraciones absolutistas de la primera mitad del siglo XIX y, sucesivamente rahabilitado, logró mantener su pensión durante la reacción fernandina desde 1818. Liberal durante el Trienio, consiguió de nuevo, esta vez tras un prolongado periodo de desgra- 
cia, volver a recobrar una moderada pensión desde 1837, para terminar su larguísima carrera de la misma forma que había comenzado: como entretenido en la Secretaría de la Embajada de España en Viena, y sin llegar a perder nunca su reputación de hombre erudito y valioso.

\section{DE VIENA A MADRID Y LONDRES (1777-1788)}

La vinculación de Virio como subalterno al servicio diplomático español se debió al Embajador con más larga titularidad en Viena, Demetrio Mahony. Designado Embajador extraordinario en la Corte de Viena en febrero de 1760 y trasformado dos años más tarde en Embajador permanente, permaneció al frente de la legación española cabe Su Majestad Imperial hasta el momento de su muerte en $1777^{4}$.

Apenas dos años antes había entrado a servir en las oficinas de la Embajada Juan Bautista Virio, y allí permaneció como meritorio o entretenido hasta que fue enviado a España en 1777.

Varios personajes relevantes, además del propio Mahony, brindaron su protección a Virio durante estos primeros años de su carrera. De manera singular, José Anduaga, luego uno de los floridablanquistas más destacados, a quien, en marzo de 1774, Grimaldi había nombrado Secretario de la legación en Austria para sustituir a Simón de las Casas. Anduaga permaneció en la capital austriaca hasta que fue llamado en 1766 a ocupar el mismo empleo en la de Londres ${ }^{5}$. D. José mantenía una estrecha y sincera amistad con el ufanoide Bernardo del Campo, su colega de la covachuela, de forma que, no es una mera coincidencia que Virio, al ser llamado a Madrid, resultase asignado como subalterno a Campo, entonces Oficial de la Primera Secretaría y Secretario del Consejo de Estado ${ }^{6}$.

Al lado de Bernardo del Campo trabajó desde su llegada a la Corte madrileña y, el 20 de julio de 1780, Virio fue nombrado Oficial segundo de la Orden de Carlos III, de la que su jefe era Secretario desde su fundación.

El gesto de su conversión en funcionario lo interpretó el húngaro como " ...una señal satisfactoria de que empezaba a acertar" "7.

Dos años y medio más tarde dio comienzo una de las etapas más interesantes en la carrera de Virio, al ser designado para servir de secretario de la misión diplomática

4 Sobre la carrera de Mahony, A.H.N. Estado, leg. 3.427 (2), n.. 3.

5 El mismo Virio manifestaría muchos años más tarde que:

"Al Excelentísimo Señor Conde de Mahony, Embajador Extraordinario de S.M. en Viena, y al Excelentísimo Señor Don José de Anduaga, Secretario de Embajada en esta Corte, en 1775, ha debido Don Juan Bautista Virio la honra de ser hoi del número de los servidores de S.M. ...".

Virio-Cevallos, Viena, 12-2-1806, A.H.N. Estado, leg. 3.436 (2).

6 Sobre Anduaga vid. A.H.N. Estado, leg, 3.422 (1). Sobre Simón de las Casas GARCIA DE LEON PIZARRO, J.: Memorias. 2 vls. Madrid, 1953, pp. 30 y 34. Acerca de Campo, A.H.N. Estado, leg. 3.416; HERNANDEZ SANCHEZ-BARBA, M.: "La Paz de 1783 y la misión de Bernardo del Campo en Londres". Estudios de Historia Moderna. Madrid, 1959, II, pp. 179-229, especialmente pp. $183-193$. También acerca de Campo, OLAECHEA, R.: "Información y acción políticá. El Conde de Aranda". Investigaciones Históricas, n.․ 7. Valladolid (1988), pp. 83-130.

7 Virio-Cevallos, Viena, 12-2-1806, A.H.N. Estado, leg. 3.436 (2). 
encomendada a Bernardo del Campo, que acababa de ser nombrado Ministro interino en Londres.

En las negociaciones que condujeron al Tratado de Versalles (1783) quedaron pendientes de conclusión con Inglaterra los artículos cuarto y séptimo de los preliminares, referidos a la presencia británica en la costa hondureña y a las relaciones mercantiles respectivamente. El Embajador en París, Aranda, recomendó encarecidamente a su secretario, Ignacio de Heredia, que hasta entonces había conducido con gran habilidad las conversaciones bilaterales hispano-británicas, para que, en calidad de Ministro interino, continuase su residencia en la capital británica, y ventilar favorablemente los difíciles negocios pendientes. A pesar de la indudable valía personal del aragonés, Floridablanca prefirió enviar allí a un hombre de su plena confianza y hechura, en vez del arandista, que, a cambio, resultó nombrado, para una plaza del Consejo de Hacienda ${ }^{8}$.

Los dos objetivos fundamentales que se encomendaron a Campo, además de insitir sobre el sempiterno problema del Peñón de Gibraltar, fueron la "vieja y enojosa cuestión" de la evacuación de la Costa de los Mosquitos, e intentar evitar la formación del nuevo tratado de comercio que pretendían los ingleses o, en caso contrario -vista la triste experiencia de 1713- procurar que fuera lo menos gravoso posible para España.

Toda la Instrucción del Primer Secretario a Campo sobre este último aspecto se resumía en:

“...Una simple máxima, a saber: que el comercio y navegación inglesa sea tratado en España al tiempo de su llegada y adeudo en la misma forma que el comercio y la navegación española fueren tratados en Inglaterra" " .

La misión de Campo, en principio ralentizada por la conflictiva política interior de la Gran Bretaña, se vio luego favorecida por la caída de Fox, y la formación de la coalición prorrealista encabezada por Pitt, con Lord Camarthen en la cartera de exteriores, lo que favoreció la continuación de las negociaciones acerca de Honduras y sobre el comercio.

Las primeras terminaron con la convención de 1786 , por la que los ingleses recibían autorización para la corta del palo campeche en una amplia zona de la Costa de los Mosquitos.

Respecto al segundo asunto, eran varias las circunstancias que concurrían. Por una parte, se trataba de acabar con las pretensiones británicas de mantener los aranceles en los términos fijados en 1713, es decir, al mismo nivel de los establecidos durante el reinado de Carlos II, lo que significaría la anulación de la reforma arancelaria

8 HERNANDEZ SANCHEZ-BARBA, M.: "La paz de 1783 y la misión de Bernardo del Campo...", pp. 179-229. OLAECHEA ALBISTUR, R. y FERRER BENIMELI, J. A.: El Conde de Aranda. Mito y realidad de un político aragonés. 2 vols. Zaragoza, 1979, I, pp. 74-78. OLAECHEA, R.: "Ignacio de Heredia y su biblioteca". En Revista de Historia Moderna. Anales de la Universidad de Alicante. Alicante (1984), pp. 211-291.

9 Instrucciones de Floridablanca a Bernardo del Campo en A.G.S. Estado, leg. 8.157. Un resumen en HERNANDEZ SANCHEZ-BARBA, M.: Vid. supra nota 8. Sobre el problema general de la Costa de los Mosquitos, CALDERON QUIJANO, J. A.: Belice 1663-1821. Sevilla, 1944. 
española de 1779-1780. Por otro lado, la complejidad del sistema aduanero y arancelario británico, que había sido causa también de un tratamiento desigual del que surgieron no pocas disputas. Precisamente a la labor desarrollada por Virio para clarificar este último aspecto se debió la posterior protección que le brindó Floridablanca.

El asesor en materias de comercio de Campo fue, en principio, Diego Gardoqui, que pronto abandonaría su empleo de Cónsul general en Inglaterra, para pasar a los Estados Unidos, sin que su participación en las negociaciones hispano-británicas tuviese ningún relieve destacado ${ }^{10}$.

Virio, secretario de Campo, se convirtió en ausencia del bizcaitarra en un valioso auxiliar en los asuntos de comercio para el Ministro, aunque el propio don Bernardo se consideraba, entre otras muchas cosas, también un experto en economía, por lo menos más que el denostado López de Lerena. Hasta poco antes de la confirmación de este último como Secretario de Hacienda, el nombre de Campo fue barajado en los mentideros cortesanos como posible sustituto del difunto Conde de Gausa ".

Desde su llegada a Londres, había comenzado Virio una minuciosa labor de recopilación de la legislación aduanera y arancelaria británica, que conectaba con la esencial preocupación demostrada por Floridablanca sobre la reciprocidad del trato en asuntos mercantiles ${ }^{12}$.

10 Para Gardoqui y su intervención, HERNANDEZ SANCHEZ-BARBA, Op. cit. GOMEZ DEL CAMPILLO, M.: Relaciones diplomáticas entre España y los Estados Unidos según los documentos del Archivo Histórico Nacional. Madrid, 1944-1945. Estudio preliminar. Expediente personal en A.H.N. Estado, leg. 3.419 (2)-3.420 (1).

1) |Anduaga| - Campo, s.l. 19-2-1785.

"Querido Campo: Desde la última que te escribí hemos tenido la novedad de haber fallecido el Conde de Gausa, y de tener por succesor suyo a aquel Don Pedro López de Lerena que se presentó en este Sitio siete años hace, viniendo de Contador de Propios y Arbitrios de Cuenca y que enviamos de Visitador del Canal de Murcia. Dicen que es natural de Valdemoro, y los muchos que le conocieron quando muchacho levantaron en Madrid tales censuras como nunca se han oído. Ya han calmado y él los ahogará enteramente con el buen modo y buena índole para el Oficio, e infinitamente mejor que la mayor parte de los que en Madrid trahían en cántaro. Algo tendrá de Judío, pues su padre era natural de un Lugarcito cerca de Velorado, aunque puede ser Christiano viejo, porque no se llama Campo, Río ni Fuentes".

Campo - Anduaga, Londres, 9-3-1785:

"Que el borrico de mi Don Fernando [Magallón] diga muy confundido haberse llevado chasco con que no sea ya Ministro de Hacienda pase, pero que una Dama Andaluza, llamada Mariquita Cuenca, que no sabe parir hijos hermosos, incurra en la misma torpeza no pase. Dela [sic] Vm. gracias por sus deseos, o por mejor decir por la intención, pues los deseos eran torpes, pecaminosos y de grave encándalo. Bueno está lo hecho y realmente creo que Lerena desempeñará muy bien dejando con su acierto desairados a los murmuradores".

A.G.S. Estado, leg. 8.157.

12 La actitud dilatoria de Floridablanca y la personal de Campo ante el tratado de comercio con Inglaterra queda reflejada con claridad en sus confidenciales a Llaguno:

"Ya verás lo que digo sobre Comercio. Toda mi vida he estado contra tratados en general, que por fin son matrimonio y esclavitud. Con Francia más que con nadie, porque lexos de tomarnos frutos, como siquiera hacen los Ingleses, nos encaja hasta vinos y aceites...".

Campo - E. Llaguno, Londres, 15-2-1787.

En confianza te digo, que el Gefe [Floridablanca] y todos aquí son de opinión de que de ningún modo nos conviene tratado de Comercio con Inglaterra, con Francia, ni con nadie. En este supuesto no te comprometas y déxate conducir desde aquí...".

E. Llaguno - Campo, s.l. 30-1-(1787). A.G.S. Estado, leg. 3.436 (2). 
El interés que demostró Campo por su subordinado en los primeros meses de 1785, después de haber pasado todo el año anterior sin pena ni gloria al quedar la actividad diplomática paralizada -por entonces el Gobiemo inglés se concentraba en las repercusiones internas de la independencia de sus colonias, y en los problemas del bill de la India y del tratado comercial con Irlanda- confirma la dedicación de Virio al trabajo, pues no đudó en recomendar vivamente la solicitud de aumento de sueldo del secretario:

“...por ser un sujeto de irreprensible conducta y de una extraordinaria constante aplicación, a pesar de su delicada salud" "13.

En las representaciones de Virio despuntaba ya un estilo literario, claro y directo, que le habría de reportar muchos favores en un mundo en el que pedimentos y memoriales eran instrumentos indispensables para moverse por las intrincadas oficinas madrileñas.

En esta ocasión, como tantos de los lloraduelos destinados en el exterior, manifestaba Virio en relación con las apreturas a que le confinaba su sueldo:

"Vivo aun privado de tal consuelo, a pesar de toda mi constancia y aplicación, pues, hasta llegar a este destino pude desempeñarme, pie con bola, pasando muchas incomodidades y ahora me veo peor que nunca (...). Es verdad que sin culpa mía tengo la mayor desgracia que el hombre puede tener, qual es la salud quebrantada de seis a siete años a esta parte, habiéndome esto precisado a remedios que aquí son exorbitantes..." ${ }^{14}$.

El anhelado aumento no tuvo lugar hasta 1786, tras la firma de la Convención sobre Honduras, que le reportó a Campo el título de Marqués, y posteriormente el nombramiento de Embajador, y a Virio un sobresueldo de 6.000 reales ${ }^{15}$.

La salud parece, pues, la razón fundamental de que Virio abandonara finalmente Inglaterra. Zanjado el asunto de la Costa de los Mosquitos, el flamante Marqués informaría de nuevo a Floridablanca de una notable recaída del estado de Virio, atribuida, como de costumbre, a la adversidad del clima, por lo que consideraba conveniente que partiera cuanto antes para realizar una gira terapéutica por el continente, en uso de una licencia que tenía concedida desde hacia algunos meses. Efectivamente, el 24 de diciembre de 1786 le fue comunicado desde Madrid la concesión de medio año de permiso, y una ayuda de costa, pero diversas circunstancias concurrieron para que

13 Campo - Floridablanca, Londres, 29-1-1785, con la solicitud de Virio fechada en 10-1-1785. A.H.N. Estado, leg. 3.436 (2).

14 Al margen anotó Floridablanca en 19-2-1785: "Más adelante". Destacaba el Ministro la carestía de Londres y lá considerable pérdida sufrida en el cambio que, fijado en 90 reales por libra en teoría, se cambiaba a 107 en la práctica, debido a "...la mucha plata que ha venido aquí". A.H.N. Estado, leg. $3.436(2)$.

15 [Floridablanca] - Campo, San Ildefonso, 17-8-1786. Oficio de Hacienda en 21-8-1786. CampoFloridablanca. Londres, 5-9-1786, con carta de agradecimiento de Virio. Poco antes, en mayo de 1786, se accedió a girarle el sueldo a Londres, pues, hasta entonces, se le pagaba vía París. [Floridablanca] Muzquiz, 8-5-1786. A.H.N. Estado, leg. 4.436 (2). 
Virio no partiera definitivamente de Inglaterra --" por justos motivos"-- hasta principios de $1788^{16}$.

\section{COMISIONADO DE FLORIDABLANCA (1788-1794)}

Los seis meses de permiso concedidos a Virio se prolongaron en la práctica un poco más, y hasta el 12 de agosto de 1788 no comunicó su llegada a la Corte, después de haber visitado a su familia y hecho una pequeña gira por Alemania ${ }^{17}$. Floridablanca, que en principio no sabía que hacer con él, mandó mantenerle el sueldo de 18.000 reales, en espera de nuevo destino, y poco después comenzó a utilizar sus servicios, como una especie de agregado en la Secretaría, en diferentes comisiones, algunas de ellas ya directamente vinculadas con asuntos de fomento. En el mes de octubre, para descargar al Ministro de negocios de menor rango, se le encomendó el examen de varias propuestas y reclamaciones de artesanos extranjeros que habían sido reclutados por el Embajador en París, Fernán-Núñez, para su establecimiento en España.

Por estas fechas, Virio ya se había acreditado como un hombre ducho y capaz en estos terrenos, y en el mes de diciembre se le encargó también confeccionar:

“...una razón exacta de los que executan las naciones que tienen costas de mar para impedir el contrabando de buques extrangeros según la nación y los casos" 18 .

El encargo no tenía nada de particular, si se considera la política dilatoria adoptada por Floridablanca ante las aspiraciones comerciales inglesas, y que la represión del contrabando fue uno de los pilares de la política del Secretario de Hacienda López de Lerena, aquel "diamante en bruto", como le denominaría la princesa María Luisa $^{19}$.

16 Campo - Floridablanca, Londres, 29-12-1786. Por extraordinario, $n^{\circ}$ 18. [Floridablanca] - Campo, Madrid, 24-12-1787. Se le concedieron 200 guineas de ayuda de costa del fondo de extraordinarios del Ministerio en Londres y la continuación del sueldo. Ibíd. Campo - Floridablanca, Londres, 15-1-1788, acusa recibo e incluye una de Virio de 14-1-1787- A.H.N. Estado, leg. 3.436 (2).

17 Virio - Floridablanca, San Ildefonso, 16-8-1788. A.H.N. Estado, leg. 3.436 (2).

18 Apud. Memorial a Su majestad, Viena, 24-10-1823. A.H.N. Estado, leg. 3.436 (2).

"...se han llegado sucesivamente varios artistas dirigidos por el señor Embaxador en París, Conde de Fernán Núñez, y no obstante que estas gentes salen de allí enterados de que no se contrae con ellos obligación alguna, se desentienden y entablan demandas y pretensiones molestas con que nos embarazan (...). Aviso a don Francisco de Escarano para que entregue a $V[\mathrm{~m}]$, y le haga cargo de todos los papeles concernientes al asunto (...). En lo respectivo a los artistas que viniesen por dirección del Señor Don Pedro de Lerena estará V[m], a lo que Su Excelencia le encargare".

El propio Virio escribía en esta ocasión que conservaba catorce oficios de Floridablanca relativos a estas comisiones.

19 Para el juicio de Anduaga sobre Lerena, vid. supra nota 12. Las referencias bibliográficas sobre Lerena suelen ser pésimas, aunque no del todo justas. ALCAZAR MOLINA, C.: El Conde de Floridablanca..., Murcia, 1934, p. 41. SARRAHIL, J., en La España llustrada..., refiere la mala opinión que Lerena le merecía, según Diario, I, p. 245 y p. 247, así como la anécdota de la frase que le dirigió María Luisa: "Floridablanca ...nos dijo que eras un diamante en bruto. Lo bruto lo hemos visto ya, pero lo de diamante no". SARRAILH, se refiere también a las diatribas de Cabarrús en Op. cit., p. 86. FERRER DEL RIO, Obras originales..., p. VI. 
Virio preparó una detallada memoria basada en el extracto de los informes que, sobre contrabando y forma de reprimirlo, se habían presentado en 1783 al Parlamento británico, cuyo extracto sería incluido más tarde en su Colección Alfabética.

\section{III.1. La Colección Alfabética de los Aranceles de la Gran Bretaña}

En un momento en el que estaba pendiente todavía la conclusión de acuerdos sobre las materias mercantiles con Inglaterra, y con Gardoqui ya de camino hacia los Estados Unidos, vimos como Virio se convirtió en el verdadero auxiliar de asuntos económicos de Campo ${ }^{20}$.

Durante los años de residencia en Londres, entre médico y remedio, Virio desarrolló una gran actividad. A las funciones de secretario, lo que significaba, entre otras cosas, llevar al día el gran volumen de correspondencia generado en un periodo de negociaciones, se unieron las funciones de Cónsul general y sus trabajos de recopilación documental destinados, en principio, a servir de instrumento técnico para la posible negociación mercantil con Inglaterra, especialmente para conocer...

“ ...las leyes y arreglos económicos de aquel país, por los que frustran normalmente los Ingleses el efecto de las concesiones ventajosas que hacen en sus tratados de comercio a otras Naciones" 21.

Y en esta labor se encuentra el origen de la que, a la postre, sería su única obra impresa: la Colección Alfabética de los Aranceles de la Gran Bretaña ${ }^{22}$.

El interés de Virio por la economía política inglesa parece remontarse a un periodo anterior a su incorporación a la secretaría londinense. Así, al menos, parece desprenderse de uno de los memoriales de Virio, en el que señalaba que durante...

"...su estancia en Inglaterra avivó las indagaciones que ya hacía en las leyes y arreglos económicos de aquel país".

Sin embargo, no parece que el propósito inical de Virio fuese destinar sus

20 En Memorial de J.B. Virio a S.M., Viena, 24-10-1823. A.H.N. Estado, leg. 3.436 (2).

"El Cónsul general Don Diego de Gardoqui volvió a España, después se fue a Estados Unidos de América y Virio atendió a las obligaciones de este consulado baxo la dirección del Señor Ministro...".

21 Virio - Cevallos, Viena, 1-10-1806, A.H.N. Estado, leg. 3.436 (2).

"Durante su estancia en Inglaterra avivó las indagaciones que ya hacía en las leyes y arreglos económicos de aquel país, por los que frustran normalmente los Ingleses el efecto de las concesiones ventajosas que hacen en sus tratados de comercio a otras naciones, y compuso de resultas de este estudio la Obra intitulada Colección Alfabética de los Aranceles de la Gran Bretaña... y de sus leyes para el fomento de la industria, pesca, navegación y comercio, deseando dar noticia del mecanismo de sus Aduanas y del empeño con que, de remotos años, han llevado aquellos Isleños su marina y Comercio al auge en que se hallaba ya, quando la conclusión de un tratado de Comercio con la Francia en 1787, abrió de nuevo campo a la codicia de aquel Pueblo mercante que persigue la industria extrangera por todos los medios imaginables hasta los hogares de las naciones amigas...".

22 VIRIO, Juan Bautista de: Colección Alfabética de los Aranceles de la Gran Bretaña, y extractos de las Leyes, Reglamentos, Ordenes y Providencias expedidas en aquel Reyno para el régimen de sus Aduanas, y fomento de su Comercio. Madrid, DDCCLXXXXII (1792). 
investigaciones a la publicación, sino que la Colección fue el resultado de una especie de encargo que le hizo Floridablanca sobre los nuevos aranceles británicos de $1787^{23}$.

Virio no se limitó a hacer una simple copia de los aranceles, sino que refundió buena parte de sus trabajos parciales sobre la legislación mercantil y de fomento británica, de acuerdo con su concepción económica, en la que destacaba la importancia concedida a la política arancelaria en la promoción de los sectores mercantil, agrícola y manufacturero para el enriquecimiento general de la nación ${ }^{24}$.

A finales de 1787 remitía a Madrid un manuscrito que resultaría decisivo en la génesis del proyecto de la Colección Alfabética, y el 17 de diciembre Floridablanca acusaba recibo al Marqués del Campo de la obra en que...

“... se manifestaba el pie en que se halla y hace el comercio de la nación inglesa con las demás naciones, y ha parecido al Rei mui importante este escrito y conveniente (...). S.M. está en atender el mérito particular que Virio ha contraído con su aplicación y trabajo en este importante objeto, y puede Vm. asegurárselo así..." 25 .

Pero la idea de formar una obra completa, y darla a la luz, se gestó en Madrid después de su regreso de Alemania, como resultado de las conversaciones mantenidas con Floridablanca en torno a algunas de las comisiones que le fueron encargadas por el Primer secretario, quien, según parece, le animó personalmente a la conclusión de la obra.

Desde 1788, Virio alternó la redacción final de la Colección con diferentes comisiones puntuales de Floridablanca, hasta que, el 24 de febrero, hizo entrega al Ministro de los cuatro gruesos volúmenes que componían el manuscrito de la obra, que causó una muy favorable impresión en Floridablanca, y que de inmediato recomendó obra y autor al Secretario de Hacienda ${ }^{26}$.

La Colección no se reducía a una fría exposición del estado de los aranceles británicos tras el Acta de Consolidación de 1787, según una ordenación alfabética por artículos, sino que en cada caso se añadía la historia de su evolución hasta ese momento con su legislación específica. En algunos de los más importantes, como la lana, se incluían además disquisiciones histórico-económicas sobre la importancia de las medidas proteccionistas adoptadas por la reina Isabel y se hacía un análisis de la evolución de su comercio con las demás naciones, etc. Pero, además, la obra constituye un verdadero registro de las leyes y providencias económicas, sacadas de fuentes originales y comentadas, en muchas ocasiones, con la opinión de los tratadistas británicos. En ella se ocupaba pormenorizadamente del estudio del sistema de organización y funcio-

23 Así, al menos parece desprenderse de la afirmación contenida en Virio - Cavallos, Viena, 1-101806- A.H.N. Estado, leg. 3.436 (2).

24 Colección de los Aranceles.... Prólogo, pp. I-VIII.

25 [Floridablanca]-Campo, s.l., 17-11-1787. Apud. Memorial a S.M., Viena, 24-10-1823- A.H.N. Estado, leg. 3.436 (2).

26 [Floridablanca] - Virio, Palacio, 24-2-1790.

-...He remitido al Señor Pedro de Lerena la Obra sobre aduanas que ha escrito Vm. con su representación de 19 del corriente y S.E. hará de ellas el uso conveniente.

No puedo menos que aplaudir a $\mathrm{Vm}$. un trabajo tan útil y de asegurarle que contribuiré gustoso a que se recompense su mérito...". 
namiento interno de las aduanas inglesas y coloniales; de las cargas sobre el tráfico y comercio interior -sisas -; de los géneros prohibidos y los sistemas de compensación y devolución de exacciones como instrumento de fomento de los fletes nacionales; de las leyes dirigidas a desarrollar el comercio con sus colonias y la recopilación de las ordenanzas coloniales. Incluía también una historia de la Compañía para las Indias Orientales desde el siglo XVII; de la legislación anticontrabando, etc. Todo ello completado con la recopilación e interpretación de la normativa legal dirigida al fomento de la construcción naval, de las pesquerías, de la navegación, y, en definitiva, de todas...

"... aquellas leyes que al paso que daban idea de la constitución de aquel país, contribuían a la mayor prosperidad de sus habitantes" 27.

Virio se ganó en esta ocasión una reputación de trabajador constante y minucioso que no perdería ya a lo largo del resto de su carrera. Además, en estos años se gestó también el proyecto con el que Virio quedaría definitivamente consagrado como un experto en temas mercantiles y de fomento, y cuyos frutos enlazan con la primera etapa gubernamental de Godoy.

Los primeros ejemplares de la Colección de los Aranceles salieron de las prensas de la viuda de Ibarra en 1792 siendo ya Secretario de Hacienda un viejo conocido de Virio, Diego de Gardoqui, que intervino con eficacia en su favor ante Godoy ${ }^{28}$.Pero en ese momento Virio llevaba ya casi dos años ocupado en una misión extraordinaria por Europa como resultado de su proyecto para el establecimiento de un Registro de providencias económicas.

\section{III.2. El proyecto de un Registro de Providencias Económicas y el grand tour euro- peo de Virio (1790-1794)}

Animado, sin duda, por el éxito de sus trabajillos para la Secretaría y, de manera muy especial, por el de los aranceles ingleses, se decidió Virio a proponer un plan de mayor envergadura que enlazaba plenamente con la tradición proyectista del siglo XVIII: la atención prestada a las experiencias y realizaciones de las demás potencias para trasplantar a España aquellas ideas que se considerasen más útiles.

Apenas dos meses después de concluir el borrador definitivo de la Colección de los Aranceles. Virio dirigió a Floridablanca un proyecto, producto de la experiencia acumulada durante su residencia en Inglaterra, que se refería básicamente al establecimiento de una oficina de registros de las providencias económicas adoptadas por los distintos gobiernos, de acuerdo con el modelo desarrollado en la Colección ${ }^{29}$.

27 Colección Alfabética de los Aranceles..., Prólogo, p. II.

28 Gardoqui - Duque de la Alcudia, 9-11-1793. Apud. Memorial a S.M., Viena, 24-10-1823. A.H.N. Estado, leg. $3.436(2)$.

29 A.H.N. Estado, leg. 2.923. "Establecimiento de registros en que deben asentarse las providencias económicas y los fomentos de las Potencias de Europa y de otras partes del mundo, correspondiendo a este efecto con los empleados del Rey u otros Españoles celosos que residieren en los países respectivos, y 
En el proyecto, fechado el 10 de abril de 1790, partía Virio de la necesidad de que el Gobierno estuviese al corriente de las experiencias y realizaciones económicas y técnicas de las diferentes potencias mediante un cuidadoso trabajo de recopilación de todas aquellas noticias relacionadas con la economía política.

Los objetivos esenciales que Virio se proponía con su registro eran:

1. Tener un conocimiento claro de los recursos y gastos de cada nación; de sus modelos impositivos, del modo en que se administraban y de los medios que utilizaban para acudir a las necesidades financieras del Estado en la forma menos gravosa.

2. Conocer exacta y pormenorizadamente las medidas de política económica y de fomento adoptadas en cada ramo de la economía para, llegado el momento, aplicar las más convenientes en España, sin caer en experimentos "arriesgados y ciegos".

3. Centralizar toda la información hasta entonces dispersa sobre aspectos técnicos relacionados con el fomento de los diversos sectores económicos y, finalmente, actuar como un "centinela continuo" sobre las acciones de los demás países...

“...para precaver los efectos ruinosos de la in[s]idiosa persuasión que siempre emplearán los representantes de las naciones extrangeras para influir y ganar a los Poderosos con razones que, dichas en sus países, serían tenidas por sofismas ridículos e intolerables" 30 .

La verdadera novedad del proyecto no estribaba en la idea de recopilar información sobre providencias económicas y aspectos técnicos, sino en estructurarla orgánicamente en una oficina centralizada. Así, en apoyo de su propuesta, recurría a la reciente designación de una comisión de dos personas por parte de la Secretaría de Hacienda para la formación de una colección de los aranceles y leyes económicas de Francia, según se dispuso por un Real Decreto de marzo de 1785.

Para que la Oficina del Registro fuese operativa, de acuerdo con su plan, sería imprescindible, y esto es una constante en todos los planes de Virio, una adecuada selección del personal encargado de su realización y...

“...mantener cerrado positiva y perpetuamente al valimiento o influxos

uniendo a él la formación ya comenzada de la balanza de comercio nacional, semejante a la que pocos años a esta parte están practicando los franceses para promover sus adelantamientos".

El expediente sobre el plan Virio lleva el encabezamiento. "Don Juan de Virio, sobre establecimiento de providencias económicas, adelantamientos de industria, etc. de naciones extrangeras". Por su parte Pilar LEON TELLO los cita como "Establecimiento de registros de aranceles y provincias [sic] económicas de las naciones europeas, y balanza de comercio nacional", en Un siglo de Fomento..., Madrid, 1980, n" 248, pp. 223-224. Pere MOLAS utiliza algunas referencias del Mss. 38.290 de la Biblioteca del Senado.

En realidad, no es fácil determinar si la idea partió del mismo Floridablanca, pues en el informe que Virio redactó en 1801 señalaba que:

"Intentaba este señor Ministro proponer a S.M. el establecimiento de una Sala de registros de providencias económicas de España y los Estados extrangeros con los que la Península tenía más relación para que constasen en estos registros el atraso o los adelantamientos de unos y otros en los muchos ramos esenciales de economía pública, y con este conocimiento pudiesen atemperarse las propias medidas, a fin de que ni siquiera se guardase igual paso con los que caminaban a mayores progresos...".

Informe de Virio, 1801. A.H.N. Estado, leg. 2.923.

30 Colección Alfabética de los Aranceles..., Voz Cónsules, en pp. 16-29. 
que podrían acelerar el nombramiento de sugetos ineptos para las plazas que se hubiesen de crear o para llenar las vacantes que ocurriesen".

La Oficina se debería componer de empleados seleccionados entre las diferentes dependencias de la Administración, sobre todo de las secretarías de la Embajadas, de los "cónsules celosos" y de los pensionados en el exterior.

Una de estas personas -"hábil, celosa, con conocimientos de comercio"-- se encargaría de formar los registros de providencias de la Gran Bretaña y los Estados Unidos; otra para los de Holanda, Imperio, Polonia, Ciudades hanseáticas y Dinamarca; una tercera para Francia, Italia, Levante y Berbería; y finalmente, otra quedaría encargada de ordenar el registro y elaborar el estado comparativo con las de España y América. Sobre esta última recaería también la labor de revisar las colecciones y papeles que fuera aconsejable dar al conocimiento público.

Cada uno de estos jefes de sección dispondría a su vez de auxiliares con los conocimientos de lenguas y de aritmética necesarios para la reducción de monedas, confección de estadillos, etc.

La responsabilidad del funcionamiento de la Oficina recaería sobre un Director -puesto que, veladamente, esperaba desempeñar el propio Virio- que distribuiría y coordinaría el trabajo, además de mantener también al día la correspondencia con las Sociedades Patrióticas sobre descubrimientos, mejoras en agricultura, manufacturas o navegación, modelos de máquinas, etc.

Para recopilar la información se utilizaría a los empleados de la red de legaciones en el exterior: secretarios, agregados, jóvenes de lenguas y a los cónsules, que, además de las noticias generales, deberían también dar cuenta detallada de los lances que ocurriesen a los españoles en los diferentes países por razones de comercio o navegación, con el fin de incluirlos en el registro y poder corregir arbitrariedades o aplicar medidas estrictas medidas de reciprocidad. En definitiva, se trataba de organizar una oficina capaz de aprovechar el potencial informativo de toda la red diplomática, consular y de los agentes españoles en el exterior, cuya utilidad era meramente circunstancial a falta de una vertebración y coordinación adecuadas ${ }^{3 !}$.

Pero antes de pasar a reflexionar acerca de la organización formal del establecimiento, el propio Virio se ofrecía para realizar un gran viaje de reconocimiento por Europa con destino final en las costas del Báltico, alegando el déficit en las relaciones mercantiles, la ausencia de agentes en aquellas latitudes y las posibilidades que para el comercio de exportación español ofrecían "...los pobladísimos países de aquella parte del Continente". Para la realización de este estudio de mercado era necesario...

“...recoger datos de Narva, Reval, Riga, Konigsberg, Danzig, Luberck, Hamburgo, Bremen, hasta Holanda; suscribir[se] a impresos y arreglar un modo que excuse el gasto de ningún empleado".

El interés de Virio sobre el Norte no era nuevo. Ya durante su viaje de 1788

31 PRADELLS NADAL, J.: "Una fuente infrautilizada. La documentación consular española del siglo XVIII". Congreso Internacional sobre Carlos III y su siglo. Madrid, 1988 (En prensa). 
había visitado aquellos lugares, y en el proyecto que presentó a Floridablanca, no ocultaba su indignación por el alto nivel de beneficios -estimado en los años de 1785 en alrededor de un 50 o $60 \%$ neto- que generaba la exportación a España de hilo y lienzos desde Hamburgo, y cuyo valor global se cifraba en unos cinco millones de pesos anuales. Lo atractivo del negocio era también uno de los principales motivos por los que el gobierno prusiano estaba particularmente interesado en desviar la salida de las manufacturas de Silesia hacia el puerto de Stettin.

Ofrecía Virio llevar a cabo la comisión con la mayor economía para, a su regreso, recoger información sobre la Balanza de Comercio francesa, visitar los Cantones suizos y tomar buena nota de los diferentes procedimientos para la construcción y conservación de caminos y canales en los diferentes territorios que cruzase en su periplo.

El éxito alcanzado por su trabajo sobre los aranceles británicos, y, posiblemente también, la españolización que en el servicio diplomático estaba llevando a cabo Floridablanca, movió al Secretario de Estado a encomendarle la realización de esta nueva comisión, de acuerdo con el plan que Virio le había presentado, pero no exento de cierta desconfianza, pues como Moñino escribiera poco antes para instrucción de la Junta Suprema de Estado, no era conveniente...

“...dejarse deslumbrar con las razones especiosas de los escritores y proyectistas" $" 32$.

Así, pues, no es completamente exacto que el proyecto del registro de providencias cayera en el vacío, sino que, por diferentes razones, no llegó a llevarse a cabo conforme el plan primitivo, aunque, como señalaremos más adelante, tuvo su continuación, con modificaciones de alcance, en la Dirección de Fomento ${ }^{33}$.

Efectivamente, en octubre Virio recibió la orden de partir con un sobresueldo de 18.000 reales anuales más para los gastos de viaje y documentación y, lo que no deja de ser otro índice significativo para su posterior trayectoria, también la de llevar consigo, en calidad de agregado, al hijo del entonces Ministro en los Estados Unidos, Diego de Gardoqui.

Poco tiempo después emprendía camino Virio en compañía de José María Gardoqui -en otros medios Gardoquito- con dirección a Francia, donde, repentinamente, nuestro comisionado resultó atacado por una "enfermedad sumamente peligrosa" que le retuvo en Lyon. Durante su larga convalecencia -explicaría años más tardeaprovechó para visitar las manufacturas de seda, y traducir y anotar la memoria del abate Bertholon sobre aquellas fábricas.

Recobrada medianamente la salud, continuó viaje, según lo previsto, por Suiza y el Tirol hasta Bohemia, en cuyo tránsito recopiló cuantos materiales pudo sobre las fábricas de vidrio y lencería. Seguidamente recorrió la Alta Lusacia -territorios com-

32 Floridablanca - Virio, 14-10-1790. Apud. Memorial a S.M. en Viena, 23-10-1823. A.H.N. Estado, leg. $3.436(2)$.

$\because$...disponga otra obra como la de Inglaterra respecto de las naciones y puertos del Báltico, tomando la ruta de Tolosa y León de Francia, Ginebra, la Suiza, el Tirol, Bohemia, Saxonia y Silesia".

La ref. de Moñino en Instrucción Reservada..., CCLXXVI, p. 254.

33 MOLAS, P.: "De la Junta de Comercio al Ministerio de Fomento...", pp. 529-556. 
prendidos entre el Elba y el Oder- visitó el Ducado de Brunnswick, en la Baja Sajonia, y la ciudad de Gotinga, con el fin de conocer personalmente sus famosos institutos literarios y completar las observaciones sobre Sajonia, Suiza y Austria, antes de dirigirse a las ciudades hanseáticas y establecerse en Hamburgo.

Pero estas son noticias que proceden de referencias muy posteriores, pues, desde su partida y hasta poco antes de ser nombrado Cónsul general, había quedado interrumpida toda correspondencia con la Corte, "...por causa de la Revolución francesa" 34

\section{DE CONSUL GENERAL EN HAMBURGO A DIRECTOR DE FOMENTO (1794-1798)}

Virio tuvo bastantes cosas que justificar, cuando restableció el contacto con su Gobierno después de casi tres años de silencio epistolar. Sin embargo, la intervención de Gardoqui resultó decisiva para la prórroga de su comisión en el Norte de Europa, e incluso para que Godoy decidiera otorgarle cierto reconocimiento y estatus oficial mediante la concesión del título de Cónsul general.

Si bien las relaciones con Gardoqui no debieron de ser modelo de una amistad ejemplar, existían, además del mutuo conocimiento personal desde los días en que ambos estuvieron destinados en Londres, algunas coincidencias en lo relativo a la necesidad de continuar con los proyectos iniciados en tiempos de Floridablanca, y dirigidos a elaborar la balanza de comercio española, así como la fugaz preceptoría de Virio a su hijo José María, cuando inició el tour europeo de 1790, contribuyen a explicar que, a finales de 1793, el Secretario de Hacienda hiciese presente a Godoy el deseo del rey de recompensar la meritoria labor que Virio había realizado con su obra sobre los aranceles ingleses.

En efecto, Godoy se ocupó del caso de Virio y, con el fin de facilitar la continuación de la comisión encomendada por Floridablanca, se le libró patente de Cónsul general para todos los puertos comprendidos entre la frontera holandesa hasta la de Rusia, a la vez que se mantenía la dotación de 36.000 reales anuales ${ }^{35}$.

La labor estrictamente consular de Virio en la ciudad hanseática, durante los dos años y medio que pasó en ella, no resultó notable desde el punto de vista de las realizaciones prácticas. Independientemente que su trabajo se viera dificultado por la repetición de "dos enfermedades serias", el tratamiento discriminatorio en materias de derechos se mantuvo, y la brega con los asuntos corrientes quedó a manos del vicecónsul honorario Joaquín de Romaña ${ }^{36}$.

34 Floridablanca Virio, 14-10-1790. Apud. Memorial a S.M., Viena, 24-10-1823. A.H.N. Estado, leg. $3.436(2)$.

35 Duque de la Alcudia - Virio, 7-5-1794. Gardoqui - Duque de Ia Alcudia, 9-11-1793. Apud. Memorial a S.M., Viena 24,10-1823. A.H.N. Estado, leg. 3.436 (2).

"Don Juan Virio presentó... por mano de mi antecesor el Señor Conde de Lerena una colección alfabética de los aranceles de la Gran Bretaña con un extracto de las leyes de sus aduanas que ha formado a costa de duro trabajo. Examinada que fue de real Orden esta colección por persona de conocido talento, y enterado S.M. de la importancia de su contenido, mandó que se imprimiese de cuenta de la real Hacienda, 
Mayor interés tuvo, en cambio, la copiosa información remitida por Virio sobre el comercio del área báltica y, en particular, del realizado desde Hamburgo, que sería utilizada no sólo para la confección de la balanza de comercio, sino para su difusión en el Almanak Mercantil de $1796^{37}$.

La negativa del monarca prusiano, por entonces muy interesado en desviar la salida de productos de Silesia hacia su puerto de Stettin, aceptar cónsules generales en los términos expresados por la patente, y la difícil situación por la que atravesaban las relaciones internacionales europeas, resultaron causas determinantes que aceleraron la llamada de Virio a Madrid para tratar sobre las ideas que había expuesto a Godoy acerca del fomento del comercio y "educación económico-política" 38 .

En 1795 había remitido Virio a su Corte varios informes con un heterogéneo conjunto de propuestas de carácter proyectista sobre el fomento del comercio y un plan que denominaría de "enseñanza económico-política", que tuvieron la fortuna de entrar de lleno en la órbita de los planteamientos reformistas que abrigaban Godoy y su círculo. Las propuestas generales de Virio no diferían en lo esencial de las que ya presentara a Floridablanca en 1790 y, prácticamente, se trata de las mismas ideas reelaboradas, pero que, en esta ocasión, llegarían a concretarse en dos líneas diferentes

para que los dependientes de ella y el comercio español tuviesen por su medio un conocimiento puntual de la administración de este ramo en aquella Potencia, así como se había hecho con los aranceles de Francia.

Ya se ha verificado la impresión de la referida obra, de que tuve el honor de presentar el Rei algunos exemplares que merecieron la soberana aceptación, como V.E. puede haber reconocido por lo [sic] que también tuve el gusto de entregarle, y considerando S.M. que el trabajo del referido Don Juan Bautista Virio fue vasto y de mucho cuidado, me manda recordárselo a V.E., como lo hago, para que se tenga en ese ministerio presente este extraordinario e importante servicio.

En el nombramiento de Virio, de 7-5-1794, se justificaba que:

"En atención a los particulares servicios que ha contraído $\mathrm{V}[\mathrm{m}]$ en la comisión que se puso a su cargo de formar registros de las leyes y providencias económicas de los estados principales de Europa, y con el fin de continuar desempeñando dicha comisión con mayor facilidad y ventaja, ha venido S.M. en nombrarle Cónsul general en la Ciudad y puerto de Hamburgo y demás puertos de toda la Costa del Báltíco desde Holanda a Rusia...".

También hay que reseñar la aportación de Molas, que confirma plenamente el aserto de la protección de Gardoqui a Virio. Gardoqui, Ministro de Hacienda desde 1791, dio un nuevo impulso a la idea de la formación de una balanza de comercio -' "una secretaría de balanza", según Canga Argüelles- que seguiría en lo fundamental el modelo que ya Virio planteara a Floridablanca en 1790 , vinculándola a una publicación: El Correo Mercantil", estudiado por Luis Miguel ENCISO en Prensa e llustración del siglo XVIII. El Correo Mercantil de España y sus Indias. Valladolid, 1958.

36 PHOL, Hans: Sozial-und Wirtschaftsgestchicte der Beziehungen Hamburg zu Spanien und dem Spanichen Amerika in der Zeit von 1740 his 1806. Wiesbaden, 1963. Sobre Romaña, A.H.N. Estado, leg. $3.451(2)$.

37 El Almanak o Calendario de Comerciantes, para el año de 1796, incorpora una memoria sobre la forma de funcionamiento del comercio y aduanas inglesas y otra sobre $\mathrm{H}$ iumburgo, precisamente los dos lugares donde Virio efectuó sus principales trabajos sobre comercio y aduanas. En los correspondientes a 1798 y 1799 el editor, Ibarra, promete la ampliación de los anteriores con los relativos a Francia, etc., pero no llegarían a aparecer. B.N. Madrid, Col. Usoz, sig. 6.833 (1796), 1.392 (1798), 6.834 (1799), 6.835 (1802) y $9.060(1804)$.

38 Apud. Memorial a S.M. Viena, 24-10-1823. A.H.N. Estado, Leg. 3.436 (2). "Por los muchos obstáculos que impiden el desempeñar en esa plaza [Hamburgo] la comisión de arreglo de registros económicos, de que está encargado (...) me parece lo más conveniente que Vm se transfiera a España por algún tiempo, y con esta ocasión hablaremos del plan de instrucción sobre el comercio...". 
en torno al Semanario de Agricultura y Artes y la Dirección de Fomento, asuntos ambos que merecen algunas referencias.

\section{IV.1. El "Semanario de Agricultura y Artes"}

La nueva etapa de colaboración directa en las tareas de fomento comenzó en 1795 cuando Virio recibió la orden de regresar a España para tratar pormenorizadamente acerca de su "instrucción de comercio".

En el mes de mayo Godoy parecía ya resuelto a llevar a cabo algunas de las propuestas presentadas por Virio y, tras la incorporación del Cónsul general a Madrid, tuvieron lugar varias entrevistas entre el Cónsul y el Favorito. En julio de 1796 concretaba Virio sus planes por escrito al Príncipe de la Paz ${ }^{39}$.

Entre el conjunto de propuestas llamó la atención de Godoy...

"...la principal de ellas, que se dirige a extender los conocimientos útiles a los labradores y artesanos por medio de los curas párrocos..." 40 .

Fruto de esta propuesta sería la aparición del Semanario de Agricultura y Artes, cuya génesis y contenido fue objeto de estudio por Fernando Díez, por lo que no entraremos en el análisis pormenorizado del periódico.

La acertada interpretación que Díez hace sobre la trayectoria de la publicación, sobre todo al destacar el optimismo del reformismo ilustrado y la hipervaloración de la posible influencia del Semanario para la transformación de las costumbres y técnicas agrícolas y manufactureras, no obsta para que se puedan hacer algunas matizaciones menores respecto a la idea primigenia de Virio. Así, por ejemplo, es necesario señalar que el Cónsul general en Hamburgo no era tan ilustradamente optimista e ingenuo como para proponer

“...un escrito concebido, teóricamente, para una amplia difusión entre las clases más sufridas de la sociedad del setecientos" 41 .

Virio planteaba la elaboración de una obra, esencialmente divulgativa, con un contenido tal que los párrocos actuaran como foco de difusión de las nuevas técnicas. En este aspecto la idea distaba de ser original, pues había sido ya formulada por Campomanes, Jovellanos o Pérez Quintero, entre otros, y había sido objeto de experimentación por las instancias oficiales en Austria y Rusia. La publicación también, y fundamentalmente, iba dirigida a los hacendados y a sus administradores, capaces no sólo de leer, sino de hacer las inversiones necesarias para las mejoras agrícolas y

39 “Ensayo de un Plan de educación económico-política”. Biblioteca del Senado, Mss. 38.290. Citado por MOLAS, P.: "De la Junta de Comercio al Ministerio de Fomento...", p. 539, nota 53. Vid. PEREZ DE GUZMAN, J.: "El protectorado del Príncipe de la Paz a las ciencias y a las artes" , en Revista de la Universidad de Madrid, 12, Madrid (1954), pp. 491-514, especialmente p. 141.

40 Oficio del Príncipe de la Paz - Virio, fechado en 4-8-1796, Apud, Memorial a S.M. Viena, 2410-1823. A.H.N. Estado, leg. 3436 (2). Vid. también DIEZ, F.: Op. cit., p. 38 y ss. 
manufactureras, sentido que enlazaba mejor con las ideas manifestadas en las Sociedades de Amigos del País. Pero, en cualquier caso, ni unos ni otros se hallaban, estrictamente, entre "las clases más sufridas de la sociedad del setecientos" 42.

Si la participación de Virio resultó decisiva en el nacimiento del Semanario su intervención en la posterior elaboración de la publicación resultó efímera, pero la documentación generada durante este período proporciona datos sustanciosos para la reconstrucción del pintoresco personaje.

Aunque contaba con el patronazgo oficial, fiel a sus ideas de que el mejor acicate para el buen funcionamiento del periódico, además de la rigurosa selección del personal, era el propio interés, pretendió organizarla como una empresa privada con aportación de capital de los tres miembros que quedaron asociados en su génesis: El presbítero Juan Antonio Melón, el químico Domingo García Fernández, y él mismo.

El desembolso inicial fue de 17.000 reales en el caso de Virio y Melón, mientras que diferencias de criterio surgidas con García Fernández, por sus escasos ánimos de implicar sus fondos personales -según Virio-; por la arbitraria mutilación que sufrió uno de sus artículos sobre la fabricación de jabón, según el químico, terminaron con la participación de éste en el periódico ${ }^{4.3}$.

La atención de Virio quedó pronto absorbida por otra faceta de su plan, y de mayor envergadura, hasta el año 1798, fecha en que, con motivo de su nueva partida hacia Hamburgo, retiró su aportación del fondo de la revista, quedando como único responsable de la publicación y de su contenido cientifista el "presbítero de superiores luces" Juan Antonio Melón, hasta que los profesores de Real Jardín Botánico se hicieron cargo del Semanario, finalmente desaparecido en $1808^{44}$.

41 DIEZ RODRIGUEZ, F.: Op. cit., p. 39.

42 Así en carta de Virio - Cevallos, Viena, 12-2-1806, podemos leer:

"Convenía que se entendiesen y comunicasen en correspondencia pública los Hacendados y Cultivadores de España sobre muchos artículos que les interesan, pues del grado de su acierto provienen los mayores o menores recursos de las Monarquías. $\mathrm{Y}$ aislados en Ciudades de provincia $\mathrm{o}$ aldeas no pueden adivinar los progresos que se hacen en otras partes. Se creyó que el destino de los curas párrocos era propio, según su primitiva institución para dar avisos oportunos con la dulzura de su Ministerio, conforme lo ha declarado solemnemente Alexandro I de Rusia hace pocos años. Era tanto más necesario quando faltaban todavía en España los establecimientos en que aprendiesen los hijos de los hacendados y Dueños de grandes señoríos los principios de agricultura y de economía rural, teórica o prácticamente, y en que se formasen los Administradores quienes, por su exemplo, introducen las mejoras sin mandatos entre los rústicos labradores. Así se han mudado la faz de Holsacia, de Saxonia, de Prusia... donde no se admite a ninguno de Administrador que no tenga testimonio de haber cursado en las escuelas de Agricultura y acreditándose cierto número de años en Haciendas grandes con testimonios de los Administradores de ellas sobre su capacidad. A vista de representación de Don Juan Virio de 14 de junio de 1796, sino S.M. en resolver la publicación de un Semanario de Agricultura y Artes sirigido a los curas párrocos...".

El texto citado en A.H.N. Estado, leg. 3436 (2).

Vid. HERR, Op. cit., p. 323, nota 43.

43 Sobre García Fernández, vid. LOPEZ PIÑERO et. al. Diccionario de la ciencia moderna..., I, pp. 378-379. GAGO, Ramón: "Aproximación al estudio de la vida y obra del químico ilustrado Domingo García Fernández (1759-1826)", en Congreso de la Sociedad Española de Historia de las Ciencias. Madrid, 1980.

44 DIEZ RODRIGUEZ. Op. cit., pp. 38-54. 


\section{IV.2. La Dirección de Fomento}

Su actividad no sólo se centró en el periódico. Durante los meses de su estancia en Madrid Virio intentó poner en pie lo que había constituido el meollo de sus propuestas y que era, de nuevo, la de formar una oficina de inteligencia en la que se coordinase información económica y técnica recopilada para servir de base a la elaboración y desarrollo coherente de una política de fomento ${ }^{45}$.

Virio atribuyó a una Junta, en realidad un conciliábulo compuesto por Bernardo de Iriarte, Cabarrús y el marqués de Iranda, que examinó sus escritos, el que Godoy resolviera poner en ejecución parte de sus propuestas, pues las ideas de Virio no tuvieron una traslación exacta del papel a los hechos.

Cuando el 3 de mayo de 1797 comunicó el Príncipe de la Paz a Virio su designación para el cargo de Director del nuevo establecimiento de fomento dependiente de la Secretaría de Estado, se habían limitado sus funciones a seguir correspondencia con los cónsules en el extranjero y con los Intendentes de provincia en el interior.

En el primero de los casos, se trataría de estar al corriente de los adelantos y novedades europeas, así como de las oportunidades de disminuir los déficits comerciales españoles mediante un mejor conocimiento de los mercados, es decir, en parte, los mismos motivos por los que Virio fue comisionado en 1790 por Floridablanca.

En el segundo, se trataba de un nuevo intento de conocer la realidad interior del país por medio de los informes de los Intendentes y la colaboración de las jerarquías eclesiásticas, de lo que existían ya numerosos precedentes desde los inicios del reinado de Felipe $\mathrm{V}^{46}$.

$\mathrm{Ni}$ los objetivos del Gobierno ni la organización formal de la nueva dependencia de la Primera Secretaría respondieron, pues, enteramente a las expectativas de Virio. Para el cargo de Director segundo fue designado Bernabé Portillo y se completaba la nómina inicial con dos oficiales, Eugenio Larruga, que procedía de la Secretaría de la Balanza, y el primer oficial de la Dirección General de Rentas, Marcos Fermín ${ }^{47}$.

Desde los primeros momentos surgieron graves desavenencias personales y de concepción del establecimiento entre Virio y Portillo, y sus enfrentamientos han dejado un interesante rastro epistolar en su búsqueda de valedores cerca de Godoy ${ }^{48}$.

45 Sobre algunos precedentes en el seno mismo de la Junta de Comercio vid. MOLAS, "De la Junta de Comercio al Ministerio de Fomento...'.

46 [P. de la Paz] - Virio, 13-5-87. Apud. Memorial a S.M. Viena, 24-10-1823. A.H.N. Estado Leg. 3.436 (2). Idem. en Estado, leg. 3.485. "Orígenes y antecedentes de la creación del Ministerio de Fomento general del Reino", en Biblioteca del Senado, Mss. 38.290. Apud. MOLAS. Op. cit., p. 541, nota 62.

Respecto al asunto de la confección de estadísticas, tanto geográficas como económicas, la literatura es muy extensa. Además de la realizada en tiempos de Floridablanca, coordinada por Palomares, quizá la mejor exposición contemporánea del problema es la que hizo SEMPERE Y GUARINOS en Biblioteca Española Económico-Política, "Memoria sobre la necesidad de una exacta descripción física y económica de España". En tomo I, Madrid, Sancha, 1801, pp. 1-36. Vid. también Príncipe de la Paz, Memorias, II, cap. XVII, pp. 124-125, especialmente nota 117. Así mismo, CAPEL, H. Geografía y Matemáticas en la España del siglo XVIII, Barcelona,1982.

47 MOLAS, P.: "De la Junta de Comercio al Ministerio de Fomento...", p. 541.

48 Así, por ejemplo, Bernabé Portillo intentaría cubrirse de las acciones de Virio con el Oficial de la Secretaria Juan José Piñuelas, a quien escribía en noviembre de 1797 sus quejas sobre el comportamiento de Virio desde que fueron nominados para la Dirección de Fomento: 
Pero fue respecto al alcance de la labor y competencias de la Dirección de Fomento donde surgieron las mayores discrepancias entre el Gobierno y Virio. Apenas un mes después de su nombramiento oficial como Director de Fomento había solicitado que, tanto a él como a Portillo, se les nombrase Secretarios del rey con ejercicio de decretos para poder extender providencias que agilizasen el funcionamiento de la Dirección, aunque sin resultado, pues, según la respuesta de Godoy, el establecimiento no estaba concebido con esa finalidad ${ }^{49}$. Mientras Godoy pensaba en la Dirección como una oficina de estudios económico-estadísticos que sirvieran de auxiliar de la decisión política, Virio continuó planteando tenazmente la necesidad de dotarla de capacidad ejecutiva hasta llegar a barajar la posibilidad de elevarla al rango de Secretaría.

Tal pretensión no era producto sólo de las aspiraciones personales de Virio, sino de la expresión de una realidad que se había comprobado en la experiencia de la Junta de Comercio, puesto que, como señalaba Molas, las críticas fundamentales dirigidas a la inoperatividad de la Junta se habían centrado precisamente en el hecho de ser un órgano consultivo en última instancia.

Otra de las aspiraciones que, con bastante coherencia, sostuvo Virio, pero que originó nuevas suceptibilidades, fue la de centralizar en la Dirección todas aquellas oficinas relacionadas con aspectos de estadística y fomento que, como la Balanza que había sido organizada en torno al Correo Mercantil o el mismo Gabinete de Máquinas, proliferaban en aquellos momentos ${ }^{50}$.

En el terreno de las realizaciones concretas, se cita por más destacada la elaboración del censo de Larruga-Godoy de 1797, aunque, en definitiva, toda la labor de la Dirección se integra en una nueva fase de ensayos en el ambiente de efervescencia de planes y proyectos que caracterizó el primer periodo del Gobierno del favorito extremeño. En realidad, las propuestas de Virio no eran sino una más de las expresiones de inquietud manifestadas por los proyectistas y reformistas de la segunda mitad del siglo XVIII, dirigidas fundamentalmente a aumentar la riqueza de la nación con el fín último de fortalecerla frente a las demás potencias, por encima de consideraciones filosóficas sobre la felicidad de sus habitantes.

En su calidad de Director se encargó Virio de actuar de consultor de obras y proyectos relacionados con los más variados asuntos de fomento, si bien era una

"He sufrido desde entonces lo que no es creíble. Este hombre [Virio] es insociable e ignorante de las cosas de España y aún más de las de las Yndias, que no ha visto ni ha entendido jamás y que, según sus principios y ocupaciones de toda su vida es incapaz [sic] de comprender.

Exerce una verdadera tiranía sobre todos nosotros. Su altanería no admite consejo ni advertencia, habiendo tomado sus medidas para que nadie se atreba a hacérsela y ha concebico unos celos tan grandes de mí, que continuamente tira a precipitarme insultándome a cada paso porque se ha engreído más allá de toda ponderación. Como por otro lado su egoísmo es el más refinado que puede verse, y su audacia no tiene límites, recelo que sorprenda la bondad de nuestro Excelentísimo con algún chisme a que es extremadamente propenso...".

Bernabé Portillo - Juan José Piñuelas, Madrid, 8-11-1797, donde hace referencia a otra carta anterior sobre lo mismo de 3-8-1797. A.H.N. Estado, leg. 3.485.

49 Virio - P. de la Paz, Madrid 21-6-1797. A.H.N. Estado, leg. 3.485. Texto reproducido por MOLAS, Op. cit., p. 542, nota 70.

50 ROMEU DE ARMAS, A. Ciencia y tecnologia en la España Ilustrada. Madrid, 1980, pp. 145$168 ; 379-397$. 
actividad para la que había sido requerido ya con anterioridad a su nombramiento, pues, además del Semanario, se le habían encomendado poco después de su llegada "diferentes comisiones muy delicadas y muy arduas". Así, por ejemplo, el 19 de agosto de 1796 fue designado para examinar con el representante diplomático francés, el ministro D'Hernam, las causas de las reclamaciones recíprocas entre los gobiernos de España y Francia. También recibió de Godoy el encargo de reflexionar sobre un posible tratado de comercio con el país vecino, en colaboración con el catalán Antonio Colombí. En marzo de 1797 había vertido ya una de sus cáusticas opiniones sobre el proyecto de un montepío de labradores presentado por Andrés de Tejada ${ }^{51}$. Luego, consolidada su posición oficial, informó sobre un discurso elaborado por Mariano Campos, en el que su autor, tras divagar sobre la importancia de la agricultura para el hombre desde los más remotos tiempos, y sazonarlo con abundantes citas latinas y unas cuantas disquisiciones sobre las costumbres agrícolas de los chinos, proponía el aumento de los plantíos de moreras, de la producción de seda y, en consecuencia, del trabajo femenino. Tampoco otro confuso plan presentado por el marqués de Palacio para introducir mejoras en el canal de Aragón, mereció mejor suerte ${ }^{52}$.

Posiblemente, la más peregrina de las comisiones se la encomendó precisamente Gardoqui, al pedirle se deshiciera de un americano empeñado en buscar el patrocinio del Gobierno español para llevar a cabo un proyectos sobre aerostatos.

Asuntos de mayor enjundia fueron por el contrario, la redacción por Virio de un proyecto de acta de navegación o su intervención en la fábrica de algodón de Avila ${ }^{53}$.

Mención aparte merecen también dos propuestas de Virio que enlazan con los esfuerzos que por entonces se realizaban para alimentar el pozo sin fondo que representaban las necesidades de guerra, y que tocaban ya con aspectos reformistas de verdadera trascendencia. La primera, fechada en noviembre de 1797 , se relacionaba con las ideas que ya había expuesto con ocasión de la creación del Semanario de Agricultura y Artes, y conectaba con el plan de instrumentalizar a los párrocos como vehículos trasmisores para el fomento agrícola.

Con el fin de solventar la escasez de medios de muchas de las parroquias, acentuar el interés de los párrocos en las mejoras agrarias y aumentar la superficie de tierra cultivada, la Dirección --lo que equivale a decir Virio-- propuso que

“...los diezmos que produzcan las tierras o frutos que se cultiven de nuevo en el Reyno desde primero de año de 1798 correspondan a los Párrocos que resid[a]n personalmente todo el año sirviendo la cura de almas en la parroquia, exceptuando sólo la parte que corresponda al Rey" 54 .

51 Virio - P. de la Paz, Madrid, 24-12-1797. A.H.N. Estado, leg. 3.485.

52 Virio - P. de la Paz, Madrid, 15-6-1797. El plan Campos fechado en Aranjuez a 14-6-1797. A.H.N. Estado, leg. 3.182, n 97. Apud. LEON TELLO, P.: Un siglo de Fomento..., p. 39. n.28. El del Marqués de Palacio al Principe de la Paz, en Aranjuez, 7-7-1797. A.H.N. Estado, leg. 2.932. Apud. LEON TELLO, P.: Un siglo de Fomento..., p. 49, n 40.

53 Virio - Cevallos, Viena, 12-2-1806. A.H.N., Estado, leg. 3.436 (2). MOLAS. Op. cit., p. 542 , nota $n^{\circ} 68$. Se refiere al proyecto de Acta de Navegación de Virio conservado en la British Library, Mss. Col. Egerton, 507, $\mathrm{n}^{\mathrm{g}} 8$, ff. 73-81.

54 Virio - P. de la Paz, Madrid, 22-11-1797. A.H.N. Estado, leg. 3.485. 
De mayor relevancia, porque se relaciona estrechamente con la primera operación desamortizadora de envergadura, será otra de las ideas que expuso el 4 de noviembre de ese mismo año, pues se refería a la

“...venta de todos los bienes raíces y demás posesiones de los Hospitales, Hospicios, casas de reclusión, de expósitos y otras obras pías establecidas en el Reyno",

que presentó con una exposición de las ventajas que tal medida reportaría a la nación y a los mismos establecimientos. El interés de Saavedra por la propuesta de Virio fue inmediato, y aunque la participación directa del proyectista en su desarrollo posterior quede un tanto oscurecida por diversas circunstancias, en septiembre de 1798, una serie de decretos ordenaban la venta de gran parte de los bienes de instituciones pías y de caridad ${ }^{55}$.

En los primeros meses de 1798 , Godoy y Cayetano Soler acordaron la reestructuración de la Dirección de Fomento que, desde el 3 de marzo, sería colocada bajo la tutela del Secretario de Hacienda. Durante los diez meses en que Virio estuvo al frente de la Dirección, y hasta poco antes de ser relevado, había tratado de perfilar los objetivos que contenía su plan de 1795 en sucesivos escritos, de manera que, el 14 de febrero de 1798, había presentado un "plan general de la Secretaría de Fomento".

El 27 de marzo, el mismo día en que fechaba un extenso informe justificativo dirigido al Ministro Saavedra, recibía Virio el oficio en que se le comunicaba el fin de su comisión como Director del establecimiento y se disponía su regreso al consulado de Hamburgo ${ }^{56}$.

\section{REGRESO A HAMBURGO. EL CONSULADO EN LIORNA Y EL RETIRO A VIENA (1798-1803)}

Virio no tardó en salir hacia su antiguo destino, de forma que el 23 de mayo se encontraba ya en París, para continuar luego su viaje hacia Alemania con el propósito de proseguir sus inspecciones antes de incorporarse a Hamburgo ${ }^{57}$.

Desde Berlín escribió repetidamente a Saavedra representando lo conveniente que sería su permanencia allí, en vez de en Hamburgo, para el mejor desarrollo de sus estudios sobre los progresos agrícolas e industriales prusianos.

55 Virio - P. de la Paz, Madrid, 4-12-1797. En Saavedra - P. de la Paz, San Lorenzo, 4-12-1797 quedaba el Ministro interesado por el asunto y se lee: "Proponga su pensamiento con mayor extensión". A.H.N. Estado, leg. 3.485 .

56 Apud. Memorial a S.M., Viena, 24-10-1823:

"Habiendo cesado las comisiones del real servicio que motivaron la venida de V.E. a España, ha venido S.M. en permitirle se restituya a su destino del Consulado general de la Saxoniá baxa. En atención al buen desempeño de sus importantes servicios, ha mandado se le continúe el sueldo que actualmente desfruta [sic] de 54.000 Reales de vellón. Paso con esta fecha al Ministerio de Hacienda la orden correspondiente... Además ha venido S.M. en conceder a V[m], una ayuda de costa de 24.000 Reales de vellón...".

57 Virio - Saavedra, París, 24-5-1790. Acusa recibo de la R.O. del 8-4-1798, A.H.N., Estado, leg. $3.436(2)$. 
Pero con el ascenso de Urquijo a la Secretaría de Estado, los propósitos de Virio de permanecer en la capital prusiana se vieron defraudados al recibir orden de regresar a la ciudad hanseática, donde los intereses mercantiles españoles eran más inmediatos. El 13 de octubre de 1798 informaba Virio al Secretario de Estado haber comunicado al vicecónsul Romaña su próxima llegada, para hacerse cargo del consulado conforme con la R.O. de 17 de septiembre ${ }^{58}$.

El segundo período de Juan Bautista Virio como titular del consulado general se extiende entre 1798 y 1802 , pero no así su residencia efectiva que resultaría mucho menor.

Problemas derivados de su permanente mala salud, y del desengaño por el fracaso de su experiencia como Director del Fomeno general, le llevaron a solicitar sucesivamente varias licencias y el traslado de aquel destino. Posiblemente influyera también en sus deseos de marcharse la pérdida relativa de categoría que había implicado el nombramiento del nuevo Ministro residente en Hamburgo, don José de Ocariz.

En cualquier caso, a comienzos de 1800 , junto con una licencia para tomar las aguas sulfurosas y bicarbonatadas de los balnearios de Carlsbad -hoy Karloby-Varycomo le prescribieron los médicos, había representado también la posibilidad de abrir una nueva sede consular en Baden, uno de los más notables centros del reformismo ilustrado alemán, famosa asimismo por sus balnearios de aguas sulfurosas, y distante tan sólo veinticinco kilómetros de Viena ${ }^{59}$.

En junio se refería de nuevo a los progresos de sus males, que le obligaron a suspender la remisión de noticias a las oficinas de Hacienda para la confección de la balanza de comercio, como se le había prevenido en el mes de febrero anterior. Conforme con las órdenes recibidas entregó antes de partir a José Ocariz el material que tenía recopilado para continuarlas cuando le fuese posible, pues faltaban por completar aún varios ramos de comercio, industria y artes.

Obtenida la licencia para viajar hasta Viena y recuperarse en los balnearios, en septiembre volvió a pedir una prórroga, pues con sus metódicas visitas a las caldas de Carlsbad y Joplitz, durante los meses de julio y agosto, no había logrado una mejoría sustancial.

La primera negativa de Madrid a abrir un nuevo consulado en Austria, no le desanimó y, poco después, volvió a intentarlo de nuevo con el pretexto de haberle recomendado los médicos alternar los baños de aguas de Baden y Carlsbad, si bien, finalmente, hizo presente que, con desprecio de su salud, no dudaría en regresar a Hamburgo si ése era el deseo del rey. No obstante, y por si acaso, fueron varios los memoriales y certificados médicos que envió a Urquijo recordando sus méritos para que se le concediese la residencia en Baden o Viena con el fin de continuar sus estudios.

El verano de 1801 debió también dedicarlo a sulfurar sus humores en Baden, pues, hasta el mes de noviembre no le encontramos de regreso en Hamburgo, con motivo de haberle comunicado Ocariz una real orden, por la que se disponía el regreso a España de Santibáñez, y la necesidad de su presencia en la ciudad hanseática.

58 Virio - Urquijo, Berlín, 13-10-1798. A.H.N. Estado, leg. 3.436 (2).

59 Virio - Saavedra, Hamburgo, 13-7-1798 y Romaña - Saavedra, Hamburgo 20-7-1798. A.H.N. Estado, leg. 3.436 (2). DOMINGUEZ ORTIZ, A.: "Ilustración europea e Ilustración española". En Códice, n² 3 Jaén (1988), pp. 37-47. 
De forma casi simultánea a su reincorporación, volvió don Juan Bautista a manifestar a Cevallos sus deseos de ser trasladado a un consulado de Francia o Italia meridional, recordando el ofrecimiento que Godoy le hizo cuando en 1798 se le relevó de la Dirección de Fomento ${ }^{60}$.

Entre las informaciones remitidas en estos años destacan las relativas a las quiebras que se sucedieron en Hamburgo durante 1799; sobre las medidas adoptadas por el Senado para la reforma del Banco de Hamburgo; la traducción de las ordenanzas sobre seguros marítimos, averías y policía del puerto ${ }^{61}$; informes sobre los impuestos y contribuciones; otros en los que reflexionaba sobre el dominio marítimo de la Hansa medieval en comparación con el que ahora ejercían los británicos y, especialmente, sobre las medidas de policía contra vagos, junto con el que envió también un detallado informe sobre el modélico instituto de caridad hamburgués

“...con noticia y modelo del horno económico o cocina de la escuela de niños del propio instituto de Hamburgo, establecimiento digno de admiración",

y que sería rescatado muchos años más tarde del archivo de la Secretaría de Estado ${ }^{62}$.

En enero de 1802 Cevallos recordó las peticiones de Virio con motivo de la vacante que en Liorna acababa de dejar el fallecimiento del cónsul Francisco de Silva y, el día 11 , se le expedía el nombramiento correspondiente a su nuevo destino.

Tras hacer entrega de los papeles consulares al Ministro Ocariz, Virio se dirigió de nuevo a Carlsbad antes de emprender viaje hacia Liorna ${ }^{63}$.

Sin duda Virio no pensaba en la posibilidad de ser destinado a Lioma cuando se refería a sus deseos de servir en un consulado con clima mediterráneo y, efectivamente, allí pasó menos de un año, pues en mayo de 1803 Cevallos se avino a concecederle el retiro anticipado, en unas condiciones económicas excepcionales, y con autorización para residir en Viena, aunque con el encargo de

"...ocuparse de meditar sobre las relaciones mercantiles de España con las demás potencias, y sobre el fomento que pueden darles los Cónsules

60 Virio - Urquijo, Hamburgo, 2-5-1800. Virio - Urquijo, Viena, 14-6-1800. Virio - Urquijo, Viena, 10-9-1800. Virio - Cevallos, Viena, 24-10-1823. Virio - Cevallos, s.l. 11-11-1801. A.H.N. Estado, leg. $3.436(2)$.

61 Vid. Virio - Cevallos, Hamburgo, 2-4-1802, en la que informaba de su próxima partida para Liorna. Con tal motivo refiere Virio:

"Siendo los seguros marítimos una de las instituciones más benéficas e indispensables a los mayores progresos del comercio, y pudiendo convenir el tener presentes los arreglos que sobre un punto tan esencial rigen en los países extrangeros, había traducido la ordenanza de seguros de este Senado, con el intento de enviarle a V.E.. La he entregado al dicho Ministro [José de Ocariz] con motivo de la orden que había recibido de dar las noticias que existiesen en este país sobre el gobierno de la marina, pues comprehende la misma ordenanza la regla que deben observar los capitanes de mar, y he añadido las leyes sobre la policía en este punto con un resumen sobre la Marina Hanseática".

62 Vid. "Archivo. Razón de los trabajos executados por el Oficial Primero Palomares". A.H.N. Estado, leg. 3.442 (2).

63 Cevallos - Virio, Madrid, 11-1-1802. Virio - Cevallos, Hamburgo, 2-4-1802. A.H.N. Estado, leg. $3.436(2)$. 
de S.M. en los Puertos Extrangeros. Será del agrado del rey el que Vm. escriba sobre esta materia lo que le dicten su experiencia y aplicación" ${ }^{64}$.

\section{REGRESO A ESPAÑA: “LOS HECHOS DE MARIA TERESA DE AUSTRIA"}

Desde su retiro en Viena, Virio cumplió puntualmente con los últimos encargos que le hiciera Cevallos, pues consta que, en noviembre de 1803 , remitió un escrito sobre las relaciones comerciales españolas con las demás naciones y, ya en enero de 1804, concluyó sus reflexiones sobre las obligaciones de los cónsules en materias de fomento.

Su pacífico retiro se vio sobresaltado por la real orden dictada el 25 de agosto de 1805 -que Virio recibió en octubre de ese mismo año- en la que se disponía el regreso a España de todos los pensionados que no tuvieran un destino fijo en el servicio exterior en el plazo de seis meses.

Virio procuró obtener la exención del decreto de residencia mediante diferentes alegaciones y, aunque en enero de 1805 se le comunicó no quedar dispensado de la orden general, sus recursos continuaron llegando cadencialmente al Secretario de Estado. En uno de ellos, fechado en febrero de 1806, exponía al mal momento que atravesaba su estado de salud desde que se atrevió a realizar dos cortos viajes a Bohemia, para visitar la casa de su hermano en Pest y "examinar las fábricas de vinos y aguardientes" de Buda. En ella hacía referencia también a estar escribiendo entonces acerca del

“... arreglo de aduanas y fomento general de España, obra que creo interesante y podrá formar la segunda parte de la que escrivió [sic] en Londres sobre el mismo asunto'.

Virio señalaba que la remitiría a España cuando estuviese terminada, si bien el verdadero motivo de la carta era solicitar se le permitiese permanecer como traductor de la Embajada de España en la ciudad imperial, por lo menos hasta su conclusión.

64 Virio - Cevallos, Liorna, 1-4-1803. Solicitaba el retiro anticipado porque:

"...valetudinario como estoi, aunque mi edad no sea más de 50 años, no me dan mis circunstancias confianza de poder llenar este destino con lucimiento...".

No accedió Cavallos a las condiciones con que pretendía el retiro, según las que conservaría el sueldo de 54.000 reales por dos años más y luego se reducirían a 24.000 , con permiso para residir en Viena. El Secretario de Estado le concedió sólo 36.000 reales para los dos primeros años y 24.000 para el resto, confirmando la autorización para residir en la capital austriaca. Pero, además, le hacía encargo expreso de meditar sobre las relaciones mercantiles en oficio separado de la misma fecha. Su sucesor en el consulado de Liorna sería Juan Ventura Bouligny. Cevallos - Virio, Aranjuez, 15-3-1803. Agradecimiento de Virio en 3-6-1803.

Virio se refiere en varias representaciones a haber enviado el primero de los trabajos citados en noviembre de $1798 \mathrm{y}$, el relativo a los cónsules en el mes de enero siguiente, pero ni entre sus papeles, ni entre los recopilados posteriormente por los Archiveros de la Primera Secretaría de Estado hemos podido localizarlos. A.H.N. Estado, leg. 3.436 (2). 
Cevallos no accedió tampoco a esta pretensión y mantuvo la resolución de que se incorporase a España "luego que su salud se lo permita" 65.

Pero don Juan Bautista no tuvo mucha prisa en recuperarse de sus achaques, y cuando se le recordó la necesidad de su regreso, sólo gracias a la intervención del Príncipe de Castelfranco, entonces Embajador en Viena, que certificó la imposibilidad de que Virio pudiese realizar tan largo viaje en sus condiciones físicas, obtuvo una nueva prórroga que le permitió retrasar su vuelta a Madrid hasta la primavera de $1807^{66}$.

Gracias a las diferentes alegaciones de Virio, sabemos que continuó sus investigaciones acerca de la economía de los dominios austriacos y alemanes, y que realizó varios viajes de inspección por Sajonia y Bohemia.

Fue en octubre de 1806, con motivo de solicitar la nueva prórroga, cuando hizo las primeras concreciones sobre el alcance de las averiguaciones que realizaba

"...sobre el modo en que la Monarquía Austriaca salió del abatimiento en que estaba al subir María Teresa al Trono Imperial".

Se refería igualmente a estar redactando una obra sobre las principales reformas llevadas a cabo por la emperatriz y su hijo y sucesor José II, el Sacristán, que había titulado, en la mejor de las tradiciones ilustradas:

"Hechos de María Teresa de Austria y de su hijo José II por ilustrar a su Nación; librar a los labradores de la indiscreción de los Señores de los feudos; extirpar vicios gremiales; levantar las artes; encaminar al comercio al Bien del Estado y reformar oportunamente las Aduanas" 67 .

La obra, que según el propio Virio, contenía “...datos positivos que en vano se buscarán en descripciones de viages, ni en historias, ni aun en obras económicas", aparece como un verdadero compendio de las realizaciones del reformismo ilustrado en los territorios dependientes de los soberanos austriacos.

Dispuesta en veinticuatro capítulos y cuatro apéndices, precedidos por una introducción con reflexiones sobre la teoría y la experiencia en economía política, dedicaba el primero de ellos a las providencias preparatorias dictadas por María Teresa de Austria en torno a la reforma de la servidumbre; a los resultados de la experiencia de la cesión de lo señoríos de la corona a arrendadores hereditarios y a la creación de

65 Virio - Cevallos, Viena, 12-2-1806. Minuta de respuesta en 17-3-1806. A.H.N. Estado. leg. $3.436(2)$.

66 Castelfranco escribió respecto al estado de Virio:

“...Yo puedo asegurar a V.E. es efectiva la causa que alega, pues, aún en un pequeño viaje que ha hecho a ver a su familia, se ha visto precisado a quedarse algunos días en un pequeño pueblo del camino. enfermo sin poder ir adelante...".

Castelfranco - Cevallos, Viena, 8-10-1806, $\mathrm{n}^{\mathrm{g}}$ 20, que acompañaba la segunda solicitud de Virio, fechada en Viena el 10-10-1806. Cevallos le concedió la prórroga con fecha de 10-11-1806. Agradecimiento de Virio desde Pest en 18-12-1806. A.H.N. Estado, leg. 3.436 (2).

67 Virio - Cevallos, 8-10-1806. A.H.N. Estado, leg. 3.436 (2). 
sociedades económico-patrióticas, con especial referencia a la de Bohemia, completados con el capítulo segundo, en el que reflexionaba sobre la importancia que los arrendamientos habían tenido en el desarrollo de la agricultura inglesa.

En los capítulos siguientes abordaba las reformas introducidas en la alta administración pública y se analizaban las llevadas a cabo en el gobierno de las provincias; contemplaba la reforma de la servidumbre en los estados hereditarios y especialmente en Hungría, su tierra natal, donde, como escribía Virio, la reacción de su "clase privilegiada", no permitió que se extendiese el benéfico influjo de las reformas de los soberanos austriacos, de forma que, a la vista de los sufrimientos de

"...aquellos agricultores y gentes industriosas, podrá parecer envidiable la suerte de los vasallos de otros Estados que ya se consideran mui agoviados".

Desde el capítulo sexto al noveno se centraba sucesivamente sobre las primeras medidas adoptadas por José II en materias económicas y en la administración; en la política de reforma religiosa y del clero; en la reforma y creación de escuelas y academias $y$, también, en desmentir algunas impresiones que circulaban en Francia sobre las universidades alemanas.

El nuevo Código de José II era el objeto del capítulo noveno, y el décimo lo dedicaba a los institutos piadosos y de caridad. La política de repoblación y colonización de nuevas tierras, el frustrado intento de introducir una "única contribución", las reformas de los mayorazgos y las medidas en contra del absentismo; el régimen de imposiciones anterior a la "única contribución" y las desastrosas consecuencias que para su desarrollo habían tenido las guerras europeas ocupaban los capítulos undécimo y duodécimo.

Al régimen señorial y su funcionamiento decía haber dedicado el extenso capítulo decimotercero, completado con las medidas de exención dictadas en favor de la cría de ganados y rompimiento de baldíos. También discurría en lo tocante a la administración municipal y sus prerrogativas; acerca de las tierras concejiles y los bosques y, finalmente, sobre la figura del "Abogado de los Vasallos".

Al régimen de contribuciones vigente en 1806 dedicaba el capítulo número catorce y a la encuesta sobre el estado de los señoríos, realizada en 1802, el decimoquinto.

Para las escuelas de agricultura y veterinaria reservó los capítulos decimosexto y decimoséptimo.

La mayor parte de las cuestiones relativas al comercio, la regulación del crédito y las medidas restrictivas promulgadas contra la usura, las manufacturas y los gremios eran tratadas en los capítulos comprendidos entre el decimoctavo y el vigésimo, mientras en el siguiente reflexionaba acerca de los judíos.

Los diferentes tratados internacionales de comercio y las sucesivas medidas de política arancelaria y aduanera eran objeto de estudio en los capítulos número veintidós y veintitrés. Por último, en el vigesimocuarto, criticaba la política seguida por los sucesores de José II desde 1780.

Dirigida fundamentalmente "a los Sabios que asisten al Rei Nuesto Señor en el grave cargo de la Administración pública", el prospecto de la obra deja traslucir en el 
fondo una idea bastante primaria en lo que toca a "...las grandes ventajas de bastarse a si mismo con el conocimiento y aprovechamiento de sus propios recursos".

Virio, que se autoconsideraba "un mero relator de las acciones buenas como también de las erróneas", pensaba que la publicación de esta parte de la obra podría

"...ser útil por coincidir en algunos aspectos con las saludables intenciones de S.M. y de su ilustrísimo Ministerio".

La segunda parte de su obra estaba compuesta por una "Colección de los Aranceles y Aduanas Austriacas desde 1755 hasta el presente" que, como en el caso de la dedicada a Inglaterra, comprendia "...las providencias que se han seguido en Aduanas y los recargos de imposiciones en bienes raíces y en los subsidios que continuaron los Soberanos sucesores de José II hasta la fecha".

Su estructura, según parece, era idéntica a la que utilizó en la Colección de los Aranceles de la Gran Bretaña, e insertaba los reglamentos y las leyes de fomento

“...concernientes a cada género nombrado en los mismos aranceles con el fin de que se viere el alcance y la concordancia de principios con que obraren los impuestos y las providencias",

con las notas aclaratorias necesarias para comprobar los efectos que, sobre cada artículo en particular, habían tenido los aranceles y cada una de las sucesivas alteraciones.

Respecto a la publicación de la "Colección de Aranceles y leyes de fomento", consideraba Virio que, por estar compuesta de "documentos puramente Ministeriales", podría tener escaso interés para el público, pero sería muy útil para los empleados de la Administración,

“...a quienes tal vez prestarán especies nuevas y darán estímulo en un ramo de tanta trascendencia".

A pesar de los circunloquios y expresiones de humildad de subalterno, la misma preocupación que demostraba por la exactitud en la traducción de algunos términos técnicos y, sobre todo su intención de acudir a su amigo el sabio Melón, que daba la casualidad que por entonces ejercía ya el cargo de Juez de Imprentas, es decir de censura, dejaban entrever, por encima de su falsa modestia, grandes esperanzas de que se costeara la impresión, aunque no fuese sino para demostrar que

"...tampoco en Austria se ha acertado de golpe en todas las advertencias que conducían a la posible perfección" 68 .

No sin gran resignación y dificultad, el acetoso Virio emprendió el largo viaje

68 Virio - Cevallos, Viena, 1-10-1806. A.H.N. Estado, leg. 3.436 (2). Sobre el reformismo ilustrado austriaco, vid. KLINGENSTEIN, Grete: "Riforma e crisi: la monarchia austriaca sotto María Teresa e Giusseppe II. Tentativo de interpretazione", Annali dell'Instituto Storico Italo-Germanico, $\mathrm{n}^{2} 7$, Bolonia (1971), pp. 93-125. 
demás de seiscientas leguas hasta España el 28 de diciembre de 1806. Del mes de marzo datan algunas cartas escritas desde París y mediado el mes de mayo llegaba a Madrid ${ }^{69}$.

En esta nueva y breve etapa de su residencia en la Corte, que no llegaría a un año, las preocupaciones esenciales de don Juan Bautista fueron, ante todo, económicas, pues el retraso en la percepción de su asignación, a cargo ahora de la Tesorería General, le colocó en una difícil situación personal que pudo sobrellevar gracias a la ayuda de Melón ${ }^{70}$.

Durante una de las audiencias que le concedió Cevallos en Aranjuez, en la que de nuevo le negó quedar exento de la orden de residencia, se le insinuó la alternativa de volver al ejercicio activo en la carrera consular, posibilidad que quedó frustrada cuando Virio solicitó el Consulado general de Londres, para lo que hubiese sido necesario promocionar a Juan Larrea que era entonces su titular ${ }^{71}$.

Pero el verdadero interés de Virio se centraba en su deseo de regresar a Viena y, fracasada la opción londinense, continuó dirigiendo sus esfuerzos, ya iniciados en su correspondencia desde Austria, al fin de obtener el patrocinio regio para proseguir su obra sobre los reinados de María Teresa y José II.

En apoyo de los memoriales que elevó desde su llegada, hizo hincapié en sus antiguos méritos pero también en algunas contribuciones más recientes. Así, por ejemplo, trató de capitalizar a participación que había tenido en el descubrimiento de un nuevo producto utilizable en las manufacturas de curtidos.

Efectivamente, a su regreso a España Virio había traído consigo unas muestras de "una producción de los bosques de Ungría [sic]" de las que se extraía una sustancia urticante para el tratamiento de las pieles. La Junta de Comercio encargó a Juan Alvarez la comprobación de si en los bosques españoles existían frutos parecidos al knoppern, pero, aunque en principio no se encontraron botones de esa especie, diferentes experimientos llevados a cabo con las agallas verdes de los robles demostraron que tenían propiedades equivalentes.

Las ventajas fundamentales del nuevo producto eran, según el informe publicado por el químico Juan Bautista Guerra, el menor coste para las manufacturas y, sobre todo, que su uso redundaría en el mejor aprovechamiento de los bosques, ya que no

69 Cartas de Virio - Cevallos, de 28-12-1806 desde Viena y de 26-4-1806 desde París, en la que manifestaba que las "...incomodidades de este viage y los daños que me causa son sumamente sensibles; pero hágase la voluntad del Rei"; y de 18-5-1806, en que comunicaba su llegada a Madrid. A.H.N. Estado, leg. $3.436(2)$.

70 Nada más llegar a Madrid Virio hizo presente a Cevallos su desastrosa situación económica y solicitaba la concesión de alguna ayuda de costa. Al respecto escribía que:

"...en curarme de una cruel Esquinencia que padecí los tres primeros meses del año, se consumió la mayor parte de los medios que tenía destinados a mi citado viage. Jamás he contraído deudas y sería [deslustre] que al cabo de años de buenos servicios me viere de tal manera".

Tampoco accedió Cevallos a la solicitud de que el sueldo de 24.000 reales le fuera pagado, como hasta entonces, por la casa de Angel María Gnecco de Génova conocedor de que la Tesorería no pagaba puntualmente. Cevallos - Virio, Madrid, 18-5-1807.

A lo largo de todo 1807 reiteraría Virio sus peticiones de abono. Así en 27-2-1807 representaba no haber cobrado en siete meses y todavía en febrero de 1808 no había podido hacer efectivo ni un real. Virio - Cevallos, Madrid, 27-12-1807 y 9-2-1808, con referencia a la ayuda económica de Melón. A.H.N. Estado, leg. $3.436(2)$. 
sería necesario descortezar los árboles como hasta entonces, de lo que, suponían, se seguiría el consiguiente aumento de la producción maderera para la construcción naval.

Sin embargo, el Ministro no demostró el mismo entusiasmo que Virio y se limitó a ordenar que se le diesen las gracias "por la comunicación de este descubrimiento desconocido en España" 72 .

De mayor interés resultó su actividad como autor de los artículos antibritánicos que, con motivo de la guerra, aparecieron en la prensa madrileña en el otoño de 1807 bajo el seudónimo de Veranio Severo.

En estos artículos, verdaderos panfletos de publicística, trataba de demostrar don Juan Bautista

“...la inhumana codicia y duplicidad del gobierno inglés exercidas en todos los tiempos, y con más estrago contra la nación española',

así como poner de manifiesto algunas de las leyes que, como las actas de navegación, más habían contribuido al progreso de la Gran Bretaña, además de reflexionar sobre el verdadero significado que para el gabinete británico guardaba el concepto de neutralidad armada.

Con ellos, según palabras del propio Virio, procuró

"...desengañar a los alucinados con incontrovertibles hechos y con las reglas más sólidas de economía política" 73 .

71 Con motivo de su presencia en Aranjuez, Cevallos insinuó a Virio la posibilidad de continuar en la carrera consular. Virio planteó algún tiempo después el de Londres como el destino más apropiado debido a la experiencia que tuvo durante cinco años como secretario de Bernardo del Campo:

“...He reflexionado que era posible que el actual Cónsul General de S.M. en la Gran Bretaña fuese promovido a otro destino, y que siendo yo el más antiguo después del de Rusia [Antonio Colombí Payet], tendría a bien tal vez S.M. en honrarme con el de Londres".

Virio - Cevallos, Aranjuez, 27-6-1807. Cevallos no pensó en la posibilidad de remover a Juna Larrea de su destino y anotó al margen de la carta de Virio: "Cuando quede vacante se resolverá". Cevalios Virio, Aranjuez, 2-3-1808. A.H.N. Estado, leg. 3.436 (2).

72 Memorial de J. B. Virio a S.M. Viena, 24-10-1824. La noticia de la aportación de Virio apareció en el número 73 del Correo Mercantil de España y sus Indias, junto con los primeros resultados del análisis de los "Knoppern" que trajo. Más tarde, en el número 99, correspondiente al jueves 10-12-1807, Apartado Artes, páginas 778-782, aparecía un informe más detallado del mismo químico con una disertación sobre su utilidad y aplicaciones. Tiempo después aparecería publicado también en los números 577 y 585 del Semanario de Agricultura y Artes, fundado por Virio y Melón, pero que se redactaba ya por los profesores del Real jardín Botánico.

Para capitalizar esta aportación Virio escribió a Cevallos: " Es un nuevo servicio, por los que le ruego contribuya a que cese la infelicidad en que me hallo, a pesar de tantos años de esfuerzo, dignándose atender las súplicas que he dirigido últimamente a V.E.", y que no eran otras que la satisfacción de los atrasos y el permiso para regresar a Viena. Virio - Cevallos, Madrid, 11-12-1807. Cevallos se limitó en esta ocasión a anotar: "Dénsele las gracias por la comunicación de este descubrimiento desconocido en España", como se hizo con fecha de 15-12-1807. A.H.N. Estado, leg. 3.436 (2).

73 El mismo motivo de la utilización de seudónimo lo explicaba Virio en una carta a Cevallos fechada en septiembre de 1807: "...Pues para evitar venganzas de satélites de una nación inhumana (...) además de que el nombre del autor nada hace en interés de la causa pública".

Virio - Cevallos, 24-10-1823. Los artículos aludidos de Veranio Severo en el Diario de Madrid que, hasta 1787 había sido el Diario Curioso, Erudito, Económico y Comercial. Virio - Campo Alange, Viena, 21-1809. A.H.N: Estado, leg 3.436 (2). 
En este sentido, sus artículos eran también una síntesis de las convicciones económicas que ya había expuesto a lo largo de los diferentes epígrafes de su Colección de Aranceles, y de la anglofobia que traslucían sus manifestaciones desde los años ochenta.

Uno de los últimos intentos de Virio para que le fuese concedido el permiso y retirarse de España, tuvo lugar en noviembre de 1807, momento en que retomó su antigua propuesta de abrir consulados en Alemania como forma de aumentar las exportaciones españolas. Sin embargo, y a pesar de haber redactado algunas precisiones al efecto por solicitud expresa de Soler, las circunstancias políticas dejaron en suspenso toda decisión al respecto ${ }^{74}$.

Entre tanto, sus últimas obras pasaron por diversas vicisitudes. Luego de haber perfilado los manuscritos sobre las reformas austriacas, se mostró más decidido a la hora de defender su calidad que en 1806 , aun reconociendo las deficiencias nacidas de la premura de su conclusión. El 8 de junio de 1807 remitió los manuscritos a Cevallos con el rango expreso de que le fueran devueltos tras su examen,

"...porque ni está el uno en estado de darse a la prensa todavía, y el grande tampoco está del todo concluido" 75 .

Al día siguiente enviaba una hojilla para que se adjuntase a la Colección y en la que, a modo de prólogo, explicaba el alcance y propósito de la obra. El doce volvió a añadir nuevas precisiones $y$, a finales del mes de junio, le fueron reintegrados para su revisión ${ }^{76}$.

Una nueva misiva de Virio fechada el 15 de julio, en la que rogaba a Cevallos enviase los manuscritos a Cayetano Soler para su examen, pues ya había introducido algunas correcciones, resulta especialmente indicada para precisar el pensamiento pragmático de Virio respecto a las ínfulas de los librecambistas. En ella se refería a que la utilidad última de la obra sería lograr que no se siguieran ideas de

"...autores de bastante nombre que, revestidos de cosmopolitas, quieren moderar prohibiciones a título de quitar travas; pretenden disminuir el contrabando y establecer supuestas máximas filantrópicas que ningún gobierno sigue sin ruina de sus propios intereses; siendo evidente que en muchas cosas debe servir de Norte la conducta de las naciones con quie-

74 En octubre de 1807 representó Virio la conveniencia de abrir nuevos consulados en Alemania aunque de forma un tanto vaga e imprecisa. Examinados por Cayetano Soler demandó desde San Lorenzo, en 17-10-1807, mayor detalle sobre los productos españoles que podrían ser objeto de exportación para reducir la abultada balanza comercial negativa. Virio redactó lo que se le pedía, pues consta que Cevallos remitió a Soler dos escritos de Virio, con fechas de 28 y 30 de noviembre, que no hemos podido localizar. Vid. Cevallos - Soler, San Lorenzo, 2-12-1807, donde se hace referencia al envío de los documentos sobre consulados en Alemania.

75 Azanza - Cevallos, Aranjuez, 8-6-1807. A.H.N. Estado, leg. 3.436 (2).

76 Virio - Cevallos, Aranjuez, 9-6-1807. Remitía la hoja en cuestión y solicitaba permiso para retirarse a Madrid. Desde la capital volvió a enviar otras notas sobre la obra y su utilidad, en 12-6-1807. A.H.N. Estado, leg. 3.436 (2). 
nes se está en relación, y no reglas escolásticas por fundadas que parezcan" 77 .

El 22 de julio Cevallos resolvió que se presentase personalmente a Cayetano Soler con su recomendación. Aunque no conocemos si la audiencia con el Secretario de Hacienda llegó a celebrarse, lo cierto es que en los primeros días de noviembre Virio se mostraba inquieto por no tener noticias sobre el uso que se hacía de sus manuscritos ${ }^{78}$.

En febrero de 1808 volvió a inistir en que se le concediese la gracia de regresar a Viena y, por fin, accedió Cevallos el 2 de marzo. Apenas un día más tarde, agradecía Virio tan gran condescendencia y rogaba se le devolviesen los manuscritos para poder continuar la obra en Austria. Por respuesta recibió un oficio, firmado por Azanza, en que se le comunicaba que, reconocida su utilidad, se había mandado sacar una copia y que los originales se le remitirían posteriormente a Viena.

Tras solicitar la concesión de pasaporte el 28 del mismo mes Juan Bautista Virio salió disparado, y muy oportunamente, de Madrid en los primeros días de abril de $1808^{79}$.

\section{VIRIO EL AFRANCESADO: CONSUL GENERAL DE JOSE I EN HAMBURGO (1809-1814)}

Virio llegó a Viena en la primera semana de junio de 1808. Todavía ignorante de los sucesos de España, el día 11 escribía a Cevallos para solicitar su agregación honorífica a la Secretaría de la Embajada, y hacer más fácil su labor de recopilación de documentos ${ }^{80}$.

Desde su regreso a la capital austriaca, impresionado sin duda por el rastro de miseria que causaron las contiendas europeas, se había dedicado fundamentalmente a buscar fórmulas con que "... proporcionar algún alivio a los numerosos pobres, viudas y huérfanos víctimas de las guerras", para lo que volvió a redactar una memoria que había formado en los tiempos de su última residencia en Hamburgo sobre los institutos

77 Virio - Cevallos, Madrid, 15-7-1807. A.H.N. Estado, leg. 4.436 (2). Un resumen acerca de la polémica proteccionistas-librecambistas en NADAL FERRERAS, J.: Comercio exterior exterior con Gran Bretaña (1777-1914). Madrid, 1978; especialmente “La política comercial española”, pp. 68-109.

78 Virio - Cevallos, s.f. [finales de octubre-inicio de noviembre] puesto que la minuta de respuesta de Cevallos lleva fecha de 5-11-1807. A.H.N. Estado, leg. 3.436 (2).

79 Virio - Cevallos, Madrid, 15-7-1807 y Azanza - Virio, 10-4-1808. Apud. Memorial a S.M., Viena, 24-10-1823. A.H.N. Estado, leg. 3.436 (2).

"Haviendo visto que es sumamente interesante el que para las providencias económicas que conviene tomar en beneficio de nuestro comercio y agricultura, se tenga presente el contenido de ambas obras, he dispuesto que, a la mayor y más posible brevedad, se saque una copia de ellas, quedando a mi cargo devolver a V. (...) pagándose por el Real erario los portes y todo gasto de conducción [de] los originales al parage de su residencia, (d)el que me avisará $\mathrm{V}$. tanto para este obgeto quanto para los encargos que el rei tenga a bien confiar a sus conocimientos y autoridad, además del aumento y prefección que quiere $V$., a fin de que le sirva también de estímulo para continuar unos trabajos tan importantes a la felicidad pública...".

Virio - Cevallos, 9-2-1808. Cavellos - Virio, Aranjuez, 3-3-1808, y Virio - Cevallos, Madrid, 28-31808. A.H.N. Estado, leg. 3.436 (2).

80 Virio - Cevallos, Viena, 11-6-1808. A.H.N. Estado, leg. 3.436 (2). 
de caridad. Con idénticas expectativas realizó también la traducción de tres memorias de la Universidad de Gotinga referentes a la caridad institucionalizada y las manufacturas y resumió brevemente las providencias que habían sido adoptadas en Austria "...en favor de los pobres, y para extirpar la mendicidad" ${ }^{81}$.

Un vacío paréntesis de pocos meses se abre en la biografía de Virio hasta que, como consecuencia de la entronización de José I, se requirió juramento de fidelidad al nuevo régimen a todos los empleados en las legaciones diplomáticas. La abdicación de Bayona en el verano de 1808 marcó el momento clave para la división entre afrancesados y partidarios de la continuidad legitimista. En torno a las Juntas, a la Suprema Central primero y a la de Regencia posteriormente, se reuniría un complejo conjunto de hombres con posiciones políticas que abarcaban un amplio espectro, en el que se incluían desde los integristas patrióticos, pasando por el amorfo conglomerado de los ilustrados constitucionalistas, hasta llegar a los protoliberales. En el llamado bando afrancesado, las matizaciones sobre los individuos no serían menores ${ }^{82}$.

Virio, que recibió la orden de prestar juramento al nuevo régimen de manos del Encargado de negocios en la capital austriaca, Diego de la Quadra, cumplió con el preceptivo trámite el 3 de noviembre siguiente ${ }^{83}$. El eclipse en que había quedado durante los últimos años desapareció y, desde ese momento demostró un fervor inusual ante la nueva situación española. En febrero de 1809 exponía al ahora Ministro de Asuntos Extranjeros, Campo Alange, su satisfacción por la elevación al trono de José I, se mostraba especialmente crítico con la situación anterior y lamentaba las reacciones protagonizadas por los "insurgentes" de las Juntas:

"Ojalá obrase en mis consúbditos igual convencimiento sobre sus verdaderos intereses, no habría insurgentes, ni tendrían que llorar los funestos efectos de los errores que han cometido" 84 .

\section{Concluía Virio que:}

"Creo que se halla en estos escritos quanto pueden dictar la previsión y la experiencia en el alivio de la humanidad, y para el establecimiento de una política benéfica, por lo qual el grande número de infelices acosados de miseria deba precisamente adoptar un modo de vida qual le convenga [a él] y a la seguridad pública".

Virio - Campo Alange, Viena, 2-2-1809. A.H.N. Estado, leg. 3.436 (2).

82 La bibliografía acerca de los afrancesados resulta cada vez más extensa. A modo de simple referencia citamos algunas de las obras clásicas, como ARTOLA, M.: Los afrancesados, Madrid, 1953. Del mismo, Antiguo Régimen y Revolución Liberal, Barcelona, 1978. ELORZA, A.: La ideología liberal en la Ilustración Españaola. Madrid, 1970. Una relación más extensa en DUFOUR, G.: "De la Ilustración al Liberalismo" En La Ilustración Española. Actas del Coloquio Internacional celebrado en Alicante, 1-4 de octubre 1985. Alicante, 1986, pp. 363-383. La respuesta del cuerpo diplomático en VILLAURRUTIA, Marqués de: El Rey José Napoleón. Madrid, 1927. MERCADER RIBA, M. "La diplomacia española de José Bonaparte'": En Homenaje a a Jaime Vicens Vives. Barcelona, 1967, II, pp. 409-425. MARTINEZ CARDOS, C. y FERNANDEZ ESPEJO, J. M.: Primera Secretaría de Estado..., Madrid, 1972, pp. CXXXIICCCIX.

83 Virio dirá haber recibido la R.O. el 1 de noviembre con un oficio de Diego de la Quadra. Realizado el juramento, lo puso en manos del Embajador de Francia, General Andreosi, que se encargó de remitirlo a Madrid junto con una carta de recomendación del Conde de Champagni a favor de Virio. Virio - Campo Alange, Viena, 2-2-1809.

84 Virio - Campo Alange, Viena, 2-2-1809. A.H.N. Estado, leg. 3.436(2). 
Hasta entones Virio había aparecido como un hombre prototípico de las corrientes del reformismo ilustrado dominantes en la España de la segunda mitad del siglo XVIII. Protegido de Floridablanca, poco menos que panegirista de Campomanes y sus ideas sobre el fomento de la industria y la educación popular, y desde luego, sin que se detecten en él signos que no estuviesen acordes con los planteamientos del absolutismo reformista ilustrado. Es más, junto con cierta admiración expresada en ocasiones acerca del pragmatismo del régimen parlamentario inglés, dejaba afluir también, como tantos otros casos de ilustrados españoles, un sentimiento anglófobo en el que se confunden, por un lado, el respeto hacia la eficacia británica, a la que atribuían el haber transformado la Gran Bretaña en primera potencia mundial, y por otro -en una confusa amalgama - un sentimiento de rechazo frontal a su pragmatismo, cuando chocaba con las convicciones morales o los sentimientos nacionales afrentados.

Varios factores contribuyeron a la inclinación de Virio hacia esta nueva postura por encima de los "presupuestos ideológicos moderantistas" [sic] que se le han atribuido ${ }^{85}$. En primer lugar, y salvo el inicial periodo de efervescencia tras el acceso de Godoy al poder, la línea reformista impulsada por los gobiernos de Carlos III había sufrido un serio revés, acentuado por la retracción preventiva ante la marejada levantada por la Revolución francesa y, aunque las opiniones no son unánimes a este respecto, en el terreno de las realizaciones, el reinado de Carlos IV, hasta la proclamación de la Constitución de Bayona en junio de 1808, aparece más próximo al despotismo ministerial que a la liberalización política, si bien, ya en las catacumbas del pensamiento político, un puñado de protoliberales abogaba por la adopción de modelos constitucionales o por el deslizamiento hacia planteamientos más próximos al liberalismo.

Virio era un hombre de la Ilustración, constitucionalista sincero, íntimamente convencido de la necesidad de moderar el ejercicio del poder, aunque fuese mediante una carta otorgada, como la napoleónica. Pero además, como tantos otros de sus contemporáneos, José Nicolás de Azara incluido, quedó impresionado por la excepcional talla -política, naturalmente-, de Napoleón.

Por encima de estos factores ideológicos, que no significan contradicción con su condición de ilustrado, otros de carácter más personal y prosaico pudieron influir en Virio en el momento de adoptar la decisión de prestar obediencia al nuevo régimen. El vil metal en primer término, puesto que, como retirado y pensionista se hubiese visto privado de sus medios de subsistencia. Por otra parte, era víctima también de un cierto resquemor por el curso que su carrera había tomado desde su cese como Director de Fomento. Al respecto resulta revelador el texto de una de las cartas enviadas a Cevallos en la que lamentaba que, después de treinta años de servicios, había sido preterido en las promociones de forma que, hasta los que habían sido sus subordinados, como Bernabé Portillo y Eugenio Larruga, habían obtenido el empleo de Intendentes de provincia, por no hablar de su amigo Melón que disfrutaba del importante cargo -que no empleo- de Juez de Imprentas ${ }^{86}$.

Entre tanto, su situación en Viena, como servidor de un gobierno filofrancés, se hizo especialmente difícil, de modo que, según informó desde Ulm, tuvo que abandonar Viena en los primeros días de marzo, para evitar las persecuciones a que quedaba

85 DIEZ RODRIGUEZ. Op. cit., p. 42.

86 Virio - Cevallos, s.f. [noviembre de 1808]. A.H.N. Estado, leg. 3.436 (2) 
expuesto, y mediado mayo se encontraba ya en París, donde, por medio del Duque de Frías, recibió un oficio, fechado el 27 de marzo de 1809, en virtud del que era nombrado, de nuevo, Cónsul general en Hamburgo ${ }^{87}$.

En la capital francesa se entretuvo algún tiempo en espera de las patentes y por la falta de medios económicos, pues hacía ya un año y medio que no recibía nada de su asignación ${ }^{88}$.

Concedidos, no sin considerable esfuerzo, 15.000 reales como parte de los atrasos se le ordenó partir inmediatamente para sustituir al encargado de negocios Ranz de Romanillos, que debía esperar su incorporación, pues el titular del Ministerio, Conde de Rechteren, hacía ya algún tiempo que se hallaba en la ciudad del Sena en uso de una licencia que, a la postre, resultó indefinida ${ }^{89}$.

En Hamburgo actuó esta vez como un verdadero agente diplomático del gobierno de Pepe Botella. El problema fundamental que se encontró tras su llegada en el mes de septiembre, fue la renuencia del Senado a reconocer su patente. En último término, las ciudades hanseáticas procuraron dilatar el reconocimiento directo del enviado de José I, por temor a sufrir represalias en los intereses de sus ciudadanos asentados en España, puesto que la mayor parte de ellos residían en los territorios dominados por los "insurgentes".

Las noticias de este período demuestran que trabajó con verdadero interés por el nuevo régimen. Además de informar sobre los acontecimientos que se producían en Europa desde la perspectiva de Hamburgo y de los movimientos militares, se ocupó también, a instancias de Cabarrús, que estaba muy preocupado entonces por sostener

87 Virio - Campo Alange, París, 16-5-1809. El 27 de marzo recibió Virio por mediación del Embajador en París, Duque de Frías, el nombramiento del Cónsul general en Hamburgo, pero su sueldo se mantenía en los 24.000 reales anuales que gozaba en su retiro. Respecto a este asunto escribía:

"Me hago cargo de la escasez de recursos que padece España en el día, y quisiera ahora haberme hecho una fortuna en mis destinos, como podría, para no ser molesto en punto de los medios de existir y de hacer mi viage; pero jamás creí deberme ocupar de obgetos agenos del Real Servicio, pues en todo país adclantado en su cultura no sobra tiempo al que lo quiera emplear con el fin de promover las mejores ideas y facilitar el acierto de las empresas ventajosas a la patria".

A.H.N. Estado, leg. $3.436(2)$.

88 En 15-7-1809 el Conde de Rechteren remitió una nueva petición de Virio sobre la falta de medios. Según minuta fechada en Madrid, 23-7-1809, se ordenó librar a favor de Virio 15.000 de los 34.000 reales que se Ie debían y cargarlos en el presupuesto del vencido mes de junio. Virio representó lo insuficiente de lá asignación en 31-8-1809, pero en 29-9-1809 se le comunicó la Orden dada a la casa Baquenault y Compañía, para el abono de esa cantidad como anticipo de Ios atrasos. A.H.N. Estado, leg. $3.436(2)$

89 La secuencia de los acontecimientos fue la siguiente: Tras la incorporación de Virio, en septiembre, Ranz comunicó al Senado la decisión de José I de restablecer el Consulado general en los mismo términos que antes de la retirada de Virio y de la decisión de Cevallos de encargar de todos los asuntos exclusivamente al minstro residente. El 28-9-1809 se dio parte de la llegada de Virio a la ciudad directorial de Liibeck para que fuera reconocido provisionalmente, hasta que se presentase la patente oficial. Al pasar tres semanas sin respuesta insistió Virio en el asunto --en 17-10-1809- a cada una de las ciudades hanseáticas por separado. Hamburgo respondió el 18 y Bremen el día 30 conformándose con la decisión que adoptase Lübeck, que continuaba en silencio.

Llegada la patente desde Madrid el 7 de noviembre -remitida en 2-10-1809- la presentó de inmedia10 a Lübeck, que el 10 de noviembre confirmaba a Virio como Cónsul general; el día 20 lo hizo Hamburgo y el 22 Bremen que, a diferencia de las anteriores, introdujo una cláusula condicional.

Extracto del Oficial de la Secretaría. Madrid, 26-1-1810. A.H.N. Estado, leg. 3.436 (2). 
de cualquier forma las endebles finanzas josefinas, de tratar con el director de la "gaceta de mayor circulación en Alemania y Estados del Norte", para incluir los avisos que se publicasen en la de Madrid sobre los vales reales y, sobre todo, de difundir los progresos en la consolidación del gobierno en contra de los insurrectos de las Juntas, mediante la inclusión de "...quantos artículos hallase para borrar los errores que se divulgan" "90.

Naturalmente, muchos de los errores dejaron de divulgarse con la entrada de las tropas francesas en Hamburgo, Bremen y Lübeck.

La anexión al Imperio francés hizo necesarias nuevas patentes consulares, circunstancia que Virio aprovechó pra hacer constar que se incluyeran en el nuevo diploma el Ducado de Holpeinschleswig, para englobar también en su distrito la ciudad danesa de Altona y otros puertos del mismo Ducado, así como también los de Mecklemburgo, Wismar y Rostock ${ }^{91}$.

Hasta que la dinámica de la guerra le envolvió en el clima de derrota de los ejércitos napoleónicos y sufriese la entrada de las tropas rusas en Hamburgo, tuvieron lugar dos importantes acontecimientos en la trayectoria personal de Virio. El primero fue contraer segundas nupcias con doña Christiana Menche, " movido por la gratitud y asistencia que precisaba su delicada salud", en el verano de $1811^{92}$. La segunda, su inclusión en la Orden de España creada por José I.

El hecho de solicitar el ingreso en la nueva Orden proporciona más datos para la reconstrucción del personaje y aporta alguna luz complementaria sobre sus orígenes y rasgos ideológicos. Cuando el 30 de marzo de 1810 pidió su inclusión en la Orden, refirió el Cónsul general que, aunque tras la firma de la Convención hispano-británica sobre la Costa de los Mosquitos en 1786, Campo -que no hay que olvidar era el Secretario de la Orden de Carlos III- le prometió recomendarle para una de las cruces de la orden carolina, le rogó que no lo hiciese

“...porque, aunque descendía de una familia noble de las más antiguas de Lorena, arruinada en las guerras, me quedaba solamente un diploma original de Enrique III, Duque de Lorena, del año 1621, que le manifesté, y no tenía medios ni posibilidad de juntar tantos documentos como se requería para cumplir con las formalidades de la Real Orden. Además de que no apreciaba una distinción en que el mérito personal no era suficiente fundamento" ${ }^{93}$.

La confirmación de su admisión como Caballero de la Orden de España, a finales de ese mismo año, le llevó a escribir, en agradecimiento, un verdadero panegírico de

90 Virio - Campo Alange, Hamburgo, 9-3-1810, $\mathrm{n}^{\circ}$ 36. Informaba de la incorporación de Hannover al reino de Westfalia y de la entrada de las tropas francesas en Hamburgo, conforme se esperaba, además de otras noticias circunstanciales. También Virio - Capo Alange, Hamburgo, 4-5-1810, $\mathrm{n}^{\mathrm{0}}$ 55, sobre debilitar las campañas de desprestigio del Gobierno que fomentaban los "insurgentes".

91 Virio - Campo alange, Hamburgo, 11-2-1811, n² 158. Se le remitieron por medio de Frías en 208-1811. El borrador de la patente, fechada en 6-8-1811 en A.H.N. Estado, leg. 3.436 (2).

92 Virio - Campo Alange, Hamburgo, 21-5-1811, $\mathrm{n}^{\circ} 184$. Solicita el preceptivo permiso para contraer matrimonio con Christiana Menche. En la de 21-5-1811, $\mathrm{n}^{2} 188$ incluía la fe de matrimonio. A.H.N. Estado, leg. 3.436 (2).

93 Virio - Campo Alange, Hamburgo, 30-3-1810, n" 43. A.H.N. Estado, leg. 3.436 (2). 
Napoleón, y especialmente de su hermano José I, en el que le calificaba de "ilustrado Soberano" que se dignó dar "...una constitución qual convenía a una nación culta" ${ }^{94}$.

\section{EL TRIUNFO DE LOS “REBELDES" Y LA RESTAURACION FERNANDINA}

A pesar del relativo vacío documental de estos años, lo más significativo de los meses de confusión, con que se inició el año de 1814, es la correspondencia que mantuvo con el Secretario de Estado del gobierno fernandino y sus poco afortunados intentos de adaptarse a las nuevas circunstancias.

En el mes de mayo de 1814 están fechadas varias cartas de Virio dirigidas a un Secretario de Estado que le era todavía desconocido ${ }^{95}$. Una de ellas la dedicaba a informar de la situación en que se hallaba la factoría que los Cinco Gremios tenían en Hamburgo; la segunda tenía un carácter diferente, pues, como resultado de la nueva situación en Europa, su anterior admiración por Napoleón parece ya apagada por completo:

"Amanece, y gracias al Todopoderoso, un nuevo orden de cosas que necesitaba la humanidad en el más alto grado" ${ }^{96}$.

Los síntomas del nuevo orden no eran otros que el reciente ajuste de la convención entre Francia y las potencias aliadas y la vuelta de los franceses a las viejas fronteras de 1792. Más paradójico parece el agradecimiento explícito al protagonismo de Inglaterra que las elementales muestras de prudencia de que dio prueba para echar tierra sobre su intrusismo y justificarse, al alegar que se había mantenido en el estricto cumplimiento de su deber de funcionario.

Los meses siguientes fueron también pródigos en confusión, incertidumbre, por lo que no pueden extrañar los nuevos errores en su apreciación de lo que sería el futuro inmediato de los acontecimientos políticos en España.

El 18 de mayo escribía a Madrid unas fruslerías sobre la conclusión definitiva de

94 Virio - Campo Alange, Hamburgo, 26-11-1810, nº 127.

"Tiempo ha que elevaba yo los ojos al autor de sucesos incomparables ["el providencial Napoleón" I con reverente admiración; pero desde que se dignó dar a la España a un ilustrado Soberano, y una constitución qual convenía a una nación culta; desde que veo los sacrificios que hace el Rei Nuestro Señor por acelerar el momento de que comienzen a gozar sus nuevos súbditos de los bienes que les prepara su fraternal solicitud, y que la Naturaleza asegura con los optimos frutos que dará un reino pingüe baxo una sabia administración, al paso que me obliga al mayor reconocimiento, me llena de tristeza que los años de vigor en que yo pudiera emplear mejor una infatigable laboriosidad, están ya disipados".

95 En carta de 23-5-1814, $\mathrm{n}^{0} 450$, proporciona noticias sobre el estado de Hamburgo tras la ocupación militar, y detalla las secuelas de la destrucción. En 24-5-1814, n' 451 informa del embargo que sufrieron de los papeles del consulado por los rusos en marzo de 1813 y manifiesta el miedo a las posibles represalias sobre su persona; el 30 justifica su permanencia en Hamburgo por ser imposible encontrar ningún medio para transferirse a París; el 3 de junio continúa con la noticias de Hamburgo, etc. A.H.N. Estado, leg. $3.436(2)$. $3.436(2)$.

96 Virio - Excmo. Sr. Secretario de Estado, Hamburgo, 8-5-1814, no 446. A.H.N. Estado, leg. 
la paz, y a la vez, aquejado de presbicia política, dejaba deslizar su satisfacción porque España

“...después de siglos de tinieblas, ha sabido darse a sí misma una constitución que, según algunos puntos esenciales que han trascendido hasta ahora, parecen asegurarle una suerte venturosa" 97 .

Pocos días más tarde llegaba a sus manos la Gaceta de Altona, por la que se enteró de la entrada del archirreaccionario Fernando VII en Madrid.

Su resolución -además de encomendarse probablemente a todos los mártires de Hungría para que el correo extraviase la carta del 18 de mayo- fue la de intentar con el Duque de San Carlos la misma operación que había utilizado con anteriores Ministros: recurrir a su larga carrera de servicios.

Para ello redactó un epistolón, en el que ofrecía los trabajos que había hecho "en el triste encierro de Hamburgo", especialmente unas observaciones que había titulado "Desengaños sobre el comercio y retóricas de comerciantes, mercaderes, etc.", destinado a servir de apéndice a los que ahora denominaba "tratados sobre la riqueza de las naciones" ". Pocas fechas más tarde volvía a la carga, esta vez en tono exculpatorio, para ofrecer un programa clásico de principios de acción económico-política ${ }^{\%}$.

Pese a sus repetidas instancias, el mutismo de la Corte fue total y no llegó a recibir respuesta a ninguna de sus cartas, completamente inútiles por otra parte, ya que el 30 de mayo había sido publicado el Real Decreto de castigo a los afrancesados.

Como en el caso anterior, Virio se enteró de su contenido por fuentes indirectas. Desde luego, sus reflexiones acerca del vengativo Decreto no podían ser más ajustadas, pues

“...debe llenar de aflicción a las víctimas, que sóla España hace hoi en Europa" ${ }^{(00)}$.

Finalmente, hubo de dar por perdida su posición y, tras dejar como depositario de los papeles del consulado al conocido librero F. Nemnich, partió de Hamburgo en julio de 1814, con intención de retirarse a Viena, no sin antes detenerse a tomar las aguas de Nenndorf en Hannover, baños que simbolizaban el fin de su carrera en activo, aunque no de su dependencia ni de su colaboración con los sucesivos Embajadores de España en la corte austriaca.

\section{EPILOGO DE UNA CARRERA}

El rastro de Virio se difumina hasta que, en 1818, el Embajador en Viena, Marqués de Casa-Irujo, recomendó a Pedro Cevallos una instancia del antiguo Cónsul

97 Virio - Excmo Sr. Secretario de Estado. A.H.N. Estado, leg. 3.436 (2).

98 Virio-Excmo. Sr. Secretario de Estado, Hamburgo, 10-6-1814. A.H.N. Estado, leg. 3.436 (2).

99 Virio - Duque de San Carlos, Hamburgo, 13-6-1814. A.H.N. Estado, leg. 3.436 (2).

100 Virio - Duque de San Carlos, Hamburgo, 28-6-1814. A.H.N. Estado, leg. 3.436 (2). 
general, para que se le volviese a reconocer la pensión de veinticuatro mil reales que había gozado hasta 1814.

En apoyo de su demanda, Martínez de Irujo hacía constar que Virio había desempeñado algunas comisiones y realizado diversas traducciones, entre ellas la impugnación al Manifiesto de los insurgentes de Buenos Aires ${ }^{101}$. Cevallos, posiblemente por el conocimiento que tenía de su persona, decidió concederle diez mil reales anuales con la expresa condición de quedar obligado a desempeñar cuantos trabajos le encomendase el Embajador ${ }^{102}$.

Una ráfaga de buena suerte representó también para Virio el que fuera precisamente Cevallos el sustituto de Martínez de Irujo en la legación vienesa, y en ella continuó sus tareas de traductor de protocolos, entre ellos el del Congreso de Viena; de informes y extractos; de estatutos de instituciones, como los del Instituto politécnico; y de un variado espectro de documentos internos, artículos de prensa, etc.

Virio, personaje que representa uno de los escasos intentos sistemáticos de acercamiento a los planteamientos del reformismo ilustrado alemán, no olvidó nunca su pasión por los temas de fomento. Todavía en 1819, remitió la traducción de los artículos aparecidos en el periódico Wanderer, sobre los resultados obtenidos en los ensayos realizados con una variedad de arroz de montaña, y que fueron a parar a la Real Sociedad Económica; otro extracto de una obra de Maximiliano Luis Fugier sobre un novedoso sistema de papel de crédito que "pretende es de valor igual al oro y la plata", etc. ${ }^{103}$.

En esta tónica de colaboración continuó también durante el Trienio, hasta que, de nuevo, sufrió la represión subsiguiente a la intervención en España de los Cien mil hijos de San Luis.

En 1823 redactó el largo memorial tantas veces citado a lo largo de estas páginas, en un renovado intento de no perder su pensión pero, como en 1814 , todos sus esfuerzos resultaron en principio inútiles, aunque extraoficialmente continuó ejecutando encargos, que incluyeron la traducción del resultado de la Dieta de Hungría en 1825, según apareció en el llesperus ${ }^{104}$.

Tras la muerte de Fernando VII, muchos de los personajes ligados al lejano movimiento afrancesado, y al más reciente de los liberales, fueron rehabilitados. Virio hubo de esperar hasta el año 1837 en que un R.D. de 28 de enero, después de dieciocho años de desgracia, y ya octogenario, le volvió a reconocer el disfrute de los diez mil reales de pensión ${ }^{105}$.

A sus ochenta y cinco años, "el laborioso don Juan Bautista Virio" todavía prosiguió durante algún tiempo realizando trabajillos para la Secretaría de la Embajada de España en Viena, pero si su muerte llegó a merecer algo más que tachar su nombre de la lista de pensionistas, yo no lo he encontrado.

101 Casa-lrujo - Cevallos, Viena, 27-1-1819. A.H.N. Estado, leg. 3.436 (2).

102 Cevallos - Virio, Madrid, 25-3-1819. A.H.N. Estado, leg. 3.436 (2).

103 Cevallos - Duque de San Fernando de Quiroga, Viena, 5-4-1820. Cevallos - Duque de San Fernando, Viena, 12-4-1820. A.H.N. Estado, leg. 3.436 (2). $3.436(2)$.

104 Joaquín de Montealegre - Duque del Infantado, Viena, 7-12- 1825. A.H.N. Estado, leg.

105 Ya en 4-7-1829 el Ministro en Viena, Joaquín Francisco Campuzano, pidió a González Salmón la concesión de 10.000 reales de pensión para Virio, pero no accedió el Primer Ministro hasta 1837. por R.O de 28-1-1837. A.H.N. Estado, leg. 3.436 (2). 